\title{
Cross Validation of Rainfall Characteristics Estimated from the TRMM PR, a Combined PR-TMI Algorithm, and a C-POL Ground Radar during the Passage of Tropical Cyclone and Nontropical Cyclone Events over Darwin, Australia
}

\author{
ANIL DEO \\ School of Earth Sciences, University of Melbourne, Melbourne, Victoria, Australia \\ S. JOSEPH MUNCHAK \\ NASA Goddard Space Flight Center, Greenbelt, Maryland \\ KEVIN J. E. WALSH \\ School of Earth Sciences, University of Melbourne, Melbourne, Victoria, Australia
}

(Manuscript received 25 April 2018, in final form 20 August 2018)

\begin{abstract}
This study cross validates the radar reflectivity $Z$; the rainfall drop size distribution parameter (median volume diameter $D_{o}$ ); and the rainfall rate $R$ estimated from the Tropical Rainfall Measuring Mission (TRMM) satellite Precipitation Radar (PR), a combined PR and TRMM Microwave Imager (TMI) algorithm (COM), and a C-band dual-polarized ground radar (GR) for TRMM overpasses during the passage of tropical cyclone (TC) and non-TC events over Darwin, Australia. Two overpass events during the passage of TC Carlos and 11 non-TC overpass events are used in this study, and the GR is taken as the reference. It is shown that the correspondence is dependent on the precipitation type whereby events with more (less) stratiform rainfall usually have a positive (negative) bias in the reflectivity and the rainfall rate, whereas in the $D_{o}$ the bias is generally positive but small (large). The COM reflectivity estimates are similar to the PR, but it has a smaller bias in the $D_{o}$ for most of the greater stratiform events. This suggests that combining the TMI with the PR adjusts the $D_{o}$ toward the "correct" direction if the GR is taken as the reference. Moreover, the association between the TRMM estimates and the GR for the two TC events, which are highly stratiform in nature, is similar to that observed for the highly stratiform non-TC events (there is no significant difference), but it differs considerably from that observed for the majority of the highly convective non-TC events.
\end{abstract}

\section{Introduction}

Tropical cyclones (TCs) are associated with extreme amounts of rainfall that cause disastrous consequences, such as flooding, landslides, and death. For effective forecasting and cloud modeling studies, the accurate representation of the characteristics of rainfall, such as the temporal and spatial distribution of intensity and the drop size distribution (DSD), is essential. The latter is a fundamental quantity for radar meteorology and remote sensing whereby it is used to describe quantities such as the rainfall rate $R$, the liquid water content

Corresponding author: Anil Deo,deoa@student.unimelb.edu.au
(LWC), and the radar reflectivity $Z$ [Munchak et al. (2012) and the references therein]. Obtaining accurate rainfall information over remote regions-for example, over oceans, where the TC duration is generally greatestis difficult, however.

Quantitative precipitation estimates (QPEs) from spaceborne instruments can be used to address this shortcoming. The Precipitation Radar (PR; the first spaceborne weather radar) of the Tropical Rainfall Measuring Mission (TRMM) satellite has successfully provided estimates of rainfall for the tropics and subtropics $\left(38^{\circ} \mathrm{N}-38^{\circ} \mathrm{S}\right)$ during its operational period from 1998 to 2015 (limited data were available in 2015). For a reliable estimate of precipitation, functions of 
calibration were implemented in the PR to ensure that the measured $Z$ is unbiased compared to a known reference (Kozu et al. 2001). Nonetheless, there could still be biases in the $Z-R$ relationship or the retrieval algorithm, and routine cross validation against ground-based measurements is instrumental for diagnosing the performance of the satellite-based estimates. Central to the evaluation of the PR measurement is the TRMM ground validation $(\mathrm{GV})$ program, which produces quality-controlled ground radar (GR) data using GR at Houston, Texas (HSTN); Melbourne, Florida (MELB); Darwin, Australia (DARW); and Kwajalein Atoll, Marshall Islands (KWAJ).

Several studies have cross validated the PR reflectivities against GRs over different regions ( $\mathrm{Li}$ et al. 2017; Park et al. 2015; Wang and Wolff 2009; Wen et al. 2011). These studies, in general, show that the disagreement between the PR and GR is larger at larger reflectivities, which is usually observed in convective events, and the average discrepancy between the PR and the GR varies between radars over different regions. Cross validation of the PR rainfall rates has also been performed by some studies (Kirstetter et al. 2013; Liao and Meneghini 2009; Liao et al. 2001; Wolff and Fisher 2008). These studies provide some insight into the association of the PR and GR rainfall rates; nonetheless, a clear consensus in the association between the two is missing because a mixture of both overestimation and underestimation by the $\mathrm{PR}$ is reported (see Table 2).

The PR is a single-frequency radar, hence DSD information retrieval is not straightforward. Algorithms have been developed to estimate the drop size parameters from the PR, and a few studies have compared these with dual-polarized GR estimates (Bringi et al. 2012; Chandrasekar et al. 2003a,b). In an early study, Chandrasekar et al. (2005) compared the drop size parameters estimated from S-band polarimetric (S-POL) GRs with the respective TRMM overpass events. The $\mathrm{PR}$ attenuation adjustment factor $\varepsilon$ and the attenuationcorrected reflectivity $Z_{c}$ were utilized to compute the median volume diameter $D_{o}$. The study was performed using two overpass events, and the GR measurements were taken from the Texas and Florida Underflight Experiment (TEFLUN) and the LargeScale Biosphere-Atmosphere Experiment (LBA) field campaigns. Chandrasekar et al. (2005) found that the PR underestimates the $D_{o}$ by $8 \%$. In a recent study, Bringi et al. (2012) compared the $D_{o}$ estimated from the KWAJ S-POL GR with those estimated from the PR and a combined TRMM Microwave Imager (TMI) and PR algorithm (Munchak and Kummerow 2011) for two overpass events. The PR $D_{o}$ was estimated using the method described by Kozu et al.
(2009). Bringi et al. (2012) found that the PR overestimates the $D_{o}$ by $11.7 \%-24.6 \%$, while the combined algorithm had a relatively smaller bias $(-0.8 \%$ to $9.7 \%)$. These studies advance our knowledge on the estimation of DSD parameters using the PR but, similar to the cross validation of rainfall rates, a consensus between the association of PR- and GR-estimated DSD parameters, over different regions, has not been established.

The primary aim of the GV program is to understand the differences in the precipitation retrievals for different meteorological and hydrological regimes (Schwaller and Morris 2011). The skill of the 2A25 algorithm varies over different terrains (ocean/land surface) and precipitation types: it is known to be more reliable over the oceans and during intense rainfall events (Meneghini et al. 2004, 2000). DSD cross-validation studies have used only non-TC events, and there is a lack of studies involving extreme events like TCs. Moreover, a comprehensive study, similar to Bringi et al. (2012), that compares the rainfall rate and DSD parameters for the DARW GR is lacking.

In this study we use TCs together with non-TC events to compare the precipitation characteristics (namely, the radar reflectivity, the DSD, and the rainfall) estimated using the PR and the Munchak and Kummerow (2011) TMI and PR combined algorithm (COM) with the DARW GR. A new framework that differs in several ways from the methodology used by the existing combined algorithm (i.e., 2B31) and is expected to provide an improved estimation of rainfall characteristics is utilized by the COM. This study seeks to investigate whether there is an added advantage of using the microwave (MW) estimates with the PR. There has been a limited validation of the COM [which is only at KWAJ by Bringi et al. (2012)], and even though the TRMM mission has ended, these results are relevant for the GPM combined algorithm, as the input datasets and methodology are similar (Grecu et al. 2016). For the cross validation here, recalibrated DARW GR data are used (Louf et al. 2018). Two TC and 11 non-TC overpass events are used. Coincident TRMM and GR overpasses during the passage of TCs over Darwin are rare because of a relatively smaller occurrence of TCs (in comparison to non-TC events) and compounded by the fact that there are not many GR sites at Darwin. Also, the frequency of TRMM overpass over Darwin is low (about two overpasses per $24 \mathrm{~h}$ ). The $D_{o}$ is one of the main parameters used in defining the analytical form of the DSD (Bringi et al. 2009; Testud et al. 2001; Ulbrich and Atlas 1998); hence, we use it here to examine the representation of the DSD, consistent with other studies (e.g., Bringi et al. 2012; Atlas et al. 1999). The outline of the paper is as follows: section 2 
describes the data and methodology, section 3 presents the results and the discussion, and section 4 summarizes the results.

\section{Data and methodology}

\section{a. Darwin C-POL radar}

The DARW C-band dual-polarized radar (C-POL), located at $12.248^{\circ} \mathrm{S}, 130.925^{\circ} \mathrm{E}$ and operated by the Australian Bureau of Meteorology (BoM), is part of the TRMM GV program and provides information on tropical rainfall (Keenan et al. (1998) and the references therein). A detailed description of the radar system is provided by Keenan et al. (1998). For the computation of the rainfall rate and DSD parameters, the horizontally polarized equivalent reflectivity factor $Z_{h}$, the differential reflectivity factor $Z_{\mathrm{dr}}$, and differential propagation phase $\Phi_{\mathrm{dp}}$ parameters are used, where the last is also used to compute the specific differential propagation phase $K_{\mathrm{dp}}$. In the $\mathrm{C}$ band, the signal suffers from significant attenuation, which is corrected for by the BoM using the Bringi et al. (2001) method.

A set of algorithms, developed by Bringi et al. (2009) using 6 months of disdrometer data during the Darwin wet season (November-March), is employed to retrieve the GR-based DSD parameter $D_{o}$. Note that the wet season would consist of TC- and non-TC-related DSD cases, so the algorithm gives a climatological representation. Previous studies have shown that there is a statistical difference between TC- and non-TC-related DSDs that necessitates the implementation of a variable DSD algorithm for rainfall retrieval (Deo and Walsh 2016; Radhakrishna and Rao 2010). Implementing these changes in the DARW GR, the PR, and the COM for a more accurate cross validation is, however, beyond the scope of this study. The $D_{o}$ algorithms for different $Z_{\mathrm{dr}}$ thresholds are as follows:

$$
\begin{aligned}
& D_{o}(\mathrm{~mm})=0.0203 Z_{\mathrm{dr}}^{4}-0.1488 Z_{\mathrm{dr}}^{3}+0.2209 Z_{\mathrm{dr}}^{2}+0.5571 Z_{\mathrm{dr}}+0.801, \quad-0.5 \leq Z_{\mathrm{dr}} \leq 1.25 \mathrm{~dB}, \\
& D_{o}(\mathrm{~mm})=0.0355 Z_{\mathrm{dr}}^{3}-0.0321 Z_{\mathrm{dr}}^{2}+1.0556 Z_{\mathrm{dr}}+0.6844, \quad 1.25 \leq Z_{\mathrm{dr}} \leq 5 \mathrm{~dB} .
\end{aligned}
$$

For the computation of the rainfall rate, the BoM employs the hybrid method of Thompson et al. (2018), which utilizes the $Z_{h}, Z_{\mathrm{dr}}$, and $K_{\mathrm{dp}}$ variables.

\section{b. TRMM PR}

We use version 7 (V7) of the PR rain profiling algorithm (also known as 2A25). The following PR data are used: attenuation-corrected reflectivity $Z_{c}(2 \mathrm{~A} 25)$, rainfall rate $R$ (2A25), rainfall type (2A23), and attenuation adjustment factor $\varepsilon(2 \mathrm{~A} 25)$. A detailed description of the rainfall profiling algorithm is given by Iguchi et al. (2009).

At $13 \mathrm{GHz}$, the PR suffers from significant attenuation and this is corrected using a combination of the surface reference technique (SRT) and the HitschfeldBordan method (Iguchi et al. 2000). Briefly, the attenuation adjustment factor $\varepsilon$ is used to adjust the initial coefficient $\alpha_{0}$ in the relation between attenuation coefficient $k$ and effective radar reflectivity factor $Z_{e}$ $\left(k=\varepsilon \alpha_{0} Z_{e}^{\beta}\right)$ in such a way that the path-integrated attenuation (PIA) estimated using the SRT matches with the PIA estimated using the Hitschfeld-Bordan method.

Kozu et al. (2009) note that estimating the attenuation adjustment factor is approximately related to estimating the DSD. Hence, using their appendix and following Bringi et al. (2012), we derive the $D_{o}$ estimator for convective and stratiform rainfall fields, which are given as follows:

$$
\begin{aligned}
\ln \left(D_{o}\right)= & -0.10+0.185 \ln (R) \\
& -1.81 \log _{10}(\varepsilon) \quad \text { convective rainfall } \\
\ln \left(D_{o}\right)= & 0.0514+0.1631 \ln (R) \\
& -1.6743 \log _{10}(\varepsilon) \quad \text { stratiform rainfall. }
\end{aligned}
$$

Note that Kozu et al. (2009) used TRMM V6 to derive the parameters, whereas we use V7. The set of parameters in their appendix is still valid for convective rainfall in V7, but it differs for stratiform rainfall (T. Iguchi, National Institute of Information and Communications Technology, 2017, personal communication). A new set of parameters (provided by Toshio Iguchi) is used here for the stratiform rainfall. The accuracy in estimating $D_{o}$ using Eqs. (3a) and (3b) also differs: Kozu et al. (2009) note that the estimation is more accurate for convective rainfall, where the SRT-based path attenuation is generally more reliable. The SRT is based on the notion that a difference between the measurements during rain and rain-free periods (a reference background) provides the information about the PIA. The method is more reliable during heavy precipitation, since there is a significant contrast between the raining column and the background reference (the attenuation is large) unlike during weak precipitation, when the contrast is weaker, and the algorithm does not have sufficient information to deviate from the default $Z-R$ 


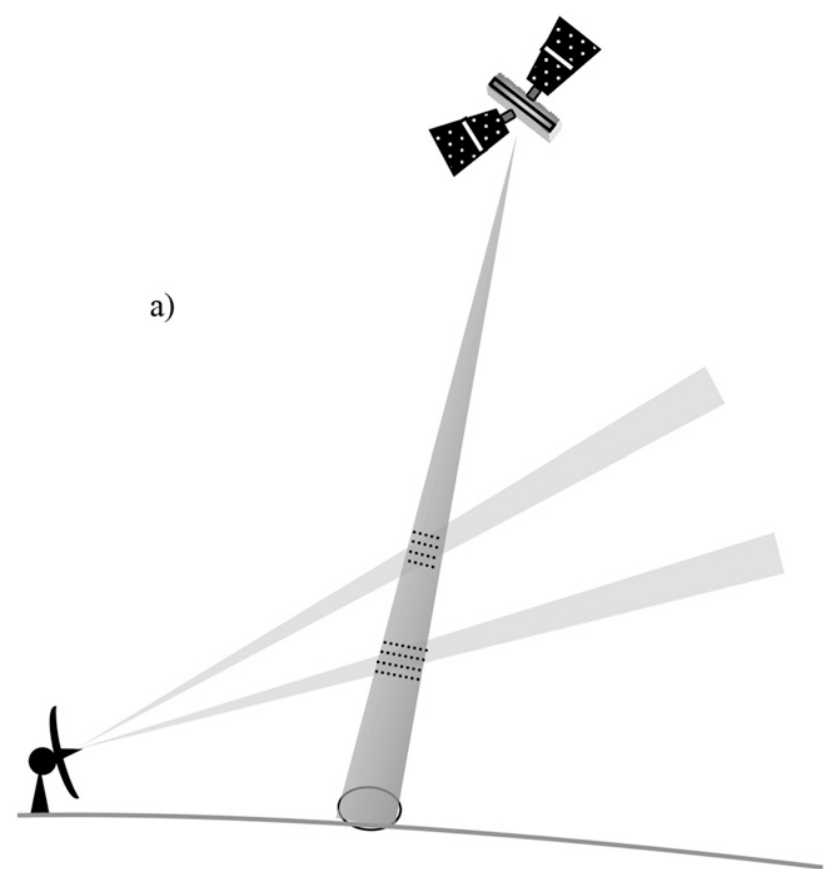

b)

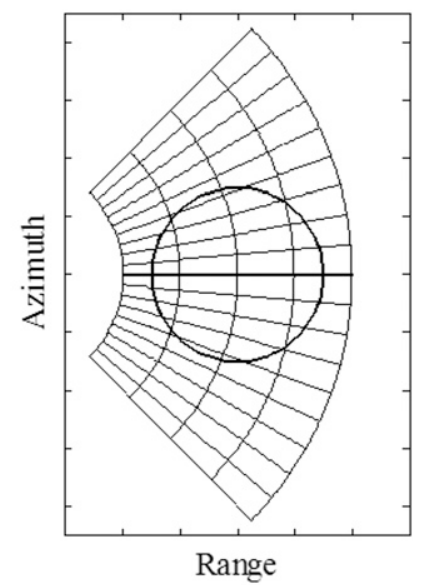

FIG. 1. Schematic of the volume matching technique. (a) Averaging of PR bins in the vertical at the intersection of the PR with the GR and (b) averaging of the GR in the horizontal at the intersection of the PR with the GR.

relationships and implied DSD properties. Moreover, ocean surfaces have less variability than land surfaces, hence the reliability is also larger over the former (Meneghini et al. 2004, 2000).

\section{c. TRMM COM}

At the core of the Munchak and Kummerow (2011) TRMM PR+TMI combined algorithm is a HitchfeldBordan reflectivity profiling algorithm, similar in many respects to the $2 \mathrm{~A} 25$ algorithm. Instead of $Z-R$ and $Z-k$ power laws, $Z-D_{o}$ power laws are fit to the $2 \mathrm{~A} 25 Z-R$ relationships for stratiform and convective rain. From these power laws and a gamma distribution

$$
N(D)=N_{o} D^{\mu} \exp \left[-\frac{(3.67+\mu)}{D_{o}}\right]
$$

with a shape parameter $\mu$ equal to 3 , all integral parameters can be determined, including $R, k$, and the extinction coefficient, single-scatter albedo, and the asymmetry parameter at each TMI frequency, which are input into the delta-Eddington radiative transfer model (Kummerow 1993). The TMI brightness temperatures are simulated at the PR resolution and then convolved to TMI resolution.

In each PR profile, three parameters are retrieved: $\varepsilon_{\mathrm{DSD}}, \varepsilon_{\mathrm{ICE}}$ and $\varepsilon_{\mathrm{CLW}}$. The $\varepsilon_{\mathrm{DSD}}$ modifies the $Z-D_{o}$ power law such that $D_{o}=\varepsilon_{\mathrm{DSD}} a Z^{b}$. Likewise, $\varepsilon_{\mathrm{ICE}}$ modifies the $Z-D_{o}$ relationship in ice phase regions of the profile and $\varepsilon_{\mathrm{CLW}}$ modifies the cloud liquid water profile. Because of the large size (approximately $40 \mathrm{~km} \times 70 \mathrm{~km}$ at $10 \mathrm{GHz}$ ) of the TMI field of view (FOV), an optimal estimation technique (Rodgers 2000) is used to optimize $\varepsilon_{\mathrm{DSD}}, \varepsilon_{\mathrm{ICE}}$, and $\varepsilon_{\mathrm{CLW}}$ over FOVs containing many PR profiles. TMI brightness temperatures and SRT PIA estimates are used as observational inputs to the optimal estimation procedure. Alternatively, the COM algorithm has the flexibility to run in radar-only mode, where only $\varepsilon_{\mathrm{DSD}}$ is modified to match the SRT PIA inputs (PIA algorithm). The flexibility allows us to examine the impact of the TMI observations on the $D_{o}$ retrieval without having to account for subtle algorithm differences between COM (in radar-only mode) and 2A25.

\section{d. Methodology for aligning the $P R$ and the $G R$}

Because of the difference in the measurement geometry of the PR and the GR (Fig. 1), the observations from both instruments need to be transformed onto a common coordinate system for a meaningful comparison. We accomplish this using the Schwaller and Morris (2011) volume matching method, which computes the PR and the GR averages at the geometric intersection of the PR with the individual GR rays. Unlike some of the other techniques, which are mostly gridded approaches (Bolen and Chandrasekar 2000, 2003; Schumacher and 
Houze 2000; Wang and Wolff 2009), this method computes the averages where there are actual observations; in other words, there is no interpolation, extrapolation, or oversampling of observations.

The matching process involves computing the averages for each PR ray at each GR sweep intersection. The along ray average of the PR at the intersection is computed in the vertical and includes those bins (at a resolution of $0.250 \mathrm{~km}$ ) that fall within the vertical resolution (beamwidth) of the GR sweep (Fig. 1a). The GR average at the intersection is computed in the horizontal, centered around the PR ray footprint (Fig. 1b), and within the PR horizontal beamwidth. In essence, the aforementioned procedure reduces the PR vertical resolution to the number of GR sweeps and the GR horizontal resolution to the number of PR rays. For a detailed description of the volumetric matching method see Schwaller and Morris (2011).

\section{e. Statistical metrics}

For the comparison to the PR, with the DARW GR taken as the reference, we use a combination of statistics. The Pearson correlation coefficient $r$ is used to measure the degree of linear association, the root-meansquare error (RMSE) to measure the average magnitude of error, and the bias (and relative bias) measures the difference between the average PR and GR values. The formulas of the statistics are as follows:

$r=\frac{\sum(\mathrm{PR}-\overline{\mathrm{PR}})(\mathrm{GR}-\overline{\mathrm{GR}})}{\sqrt{\sum(\mathrm{PR}-\overline{\mathrm{PR}})^{2}} \sqrt{\sum(\mathrm{GR}-\overline{\mathrm{GR}})^{2}}}$,

bias $=\frac{\sum_{i=1}^{n}\left(\mathrm{PR}_{i}-\mathrm{GR}_{i}\right)}{n}$,

relative bias $=\frac{\text { bias }}{\overline{\mathrm{GR}}}$,

root-mean-square error $(\mathrm{RMSE})=\sqrt{\frac{1}{n} \sum_{i=1}^{n}\left(\mathrm{PR}_{i}-\mathrm{GR}_{i}\right)^{2}}$,

relative RMSE $=\frac{\mathrm{RMSE}}{\overline{\mathrm{GR}}}$,

where $\overline{\mathrm{PR}}$ and $\overline{\mathrm{GR}}$ are the mean of the PR and GR measurements, respectively.

The uncertainty in these statistics is computed using a bootstrapping method (Efron and Tibshirani 1993) that involves resampling of the data. About 10000 resamples are created upon which bootstrapping is applied at the $95 \%$ confidence level. The 50th percentile is presented as the statistic, and the $2.5 \mathrm{nd}$ and 97.5 th percentiles as the upper and lower bounds, respectively, for the errors (confidence interval). The overlapping error bars between two or more sets of statistics imply a difference is not significant at the $95 \%$ confidence level.

\section{Results and discussion}

\section{a. Case descriptions}

Overpass events during the passage of TC Carlos (year 2011) are used as case studies for the cross validation of PR and COM rainfall characteristics during the passage of TCs. TC Carlos, after forming near Darwin (track shown in Fig. 2a), stayed in the vicinity of Darwin for more than a day before heading southwest. During its passage, the TC brought copious amount of rainfall in excess of $300 \mathrm{~mm} \mathrm{day}^{-1}$ over the Darwin region (http:// www.bom.gov.au/cyclone/history/carlos.shtml).

Two TRMM overpass events over the Darwin site occurred during the passage of TC Carlos: (i) on 15 February 2011 (Fig. 2a) and (ii) on 17 February 2011 (Fig. 2b). Figures $2 \mathrm{a}$ and $2 \mathrm{~b}$ show the GR reflectivity plan position indicators (PPIs; which is a display of measurements at a radial distance from the GR) of the two TC events, respectively, at an altitude of $3.5 \mathrm{~km}$. The 15 February event (Fig. 2a) has larger spatial coverage of rainfall than the 17 February event (Fig. 2b), which could be related to the distance of the TC center from the Darwin station, as the former is closer $(112 \mathrm{~km})$ than the latter $(167 \mathrm{~km})$.

In addition to these two TC events, 11 non-TC events are also used to examine the correspondence of the spaceborne instruments with the DARW GR (Table 1 lists the overpass events and their corresponding TRMM orbit numbers). These non-TC events are from the 2011 and 2012 Australian summer/monsoon seasons, which usually fall from November to April. Unlike TC events, which are of synoptic scale, non-TC events could be of a relatively smaller size (some are less than $1 \mathrm{~km}$, especially convective events). Thus, TRMM overpass events that had at least 100 grid points within $100 \mathrm{~km}$ from the Darwin site are used for non-TC events. The events considered here encompass both stratiform and convective rainfall with some being highly stratiform and some being highly convective. As an example, Figs. $2 \mathrm{c}$ and $2 \mathrm{~d}$ show the PPIs of widespread events that occurred on 13 January 2012 and 13 March 2012 respectively. These two events are also frequently used in the latter sections of this paper as case studies for non-TC events. Their spatial coverage of reflectivity is large (somewhat similar in size to the two TCs in the radar field of view) and their precipitation type is largely stratiform (similar to the two 

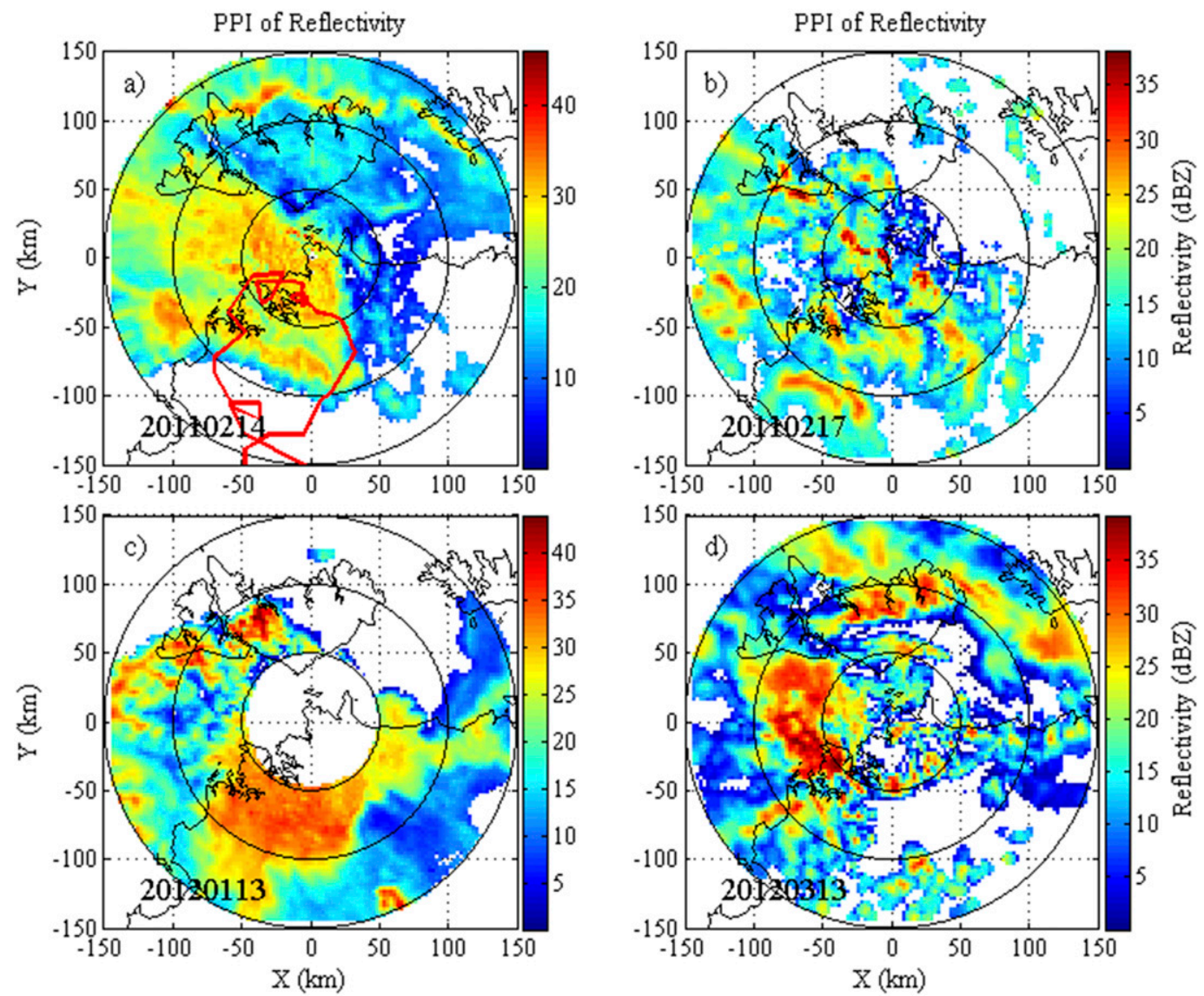

FIG. 2. GR reflectivity at a constant altitude of $3.5 \mathrm{~km}$ for the two TC Carlos events (15 and 17 Feb 2011) and for two non-TC widespread events (13 Jan and 13 Mar 2012) within a radial distance of $150 \mathrm{~km}$ around the GR. The plot in red in (a) shows the track of TC Carlos.

TC events), which makes them suitable to be used for a comparative analysis against the TC events, especially for precipitation- and terrain-type separation.

\section{b. Comparison of reflectivity}

Using the volume matching technique discussed in section 2, data are transformed onto a common 3D coordinate system. Since the PIA is used both in the 2A25 and the COM, its analysis is also included at times to understand the differences (if there are any) between the latter two products. Figure 3 shows the matched PR-GR and COM-GR reflectivity PPIs of the two TC and the two non-TC case events (shown in Fig. 2) for the $1.3^{\circ} \mathrm{GR}$ elevation sweep. A good spatial match of the $\mathrm{PR}$ and the COM with the GR is observed. The missing data in the PR near the GR origin point are attributed to ground clutter in the PR at low altitudes that has been accordingly filtered by the PR algorithm. The PR-GR spatial pairing is also missing at some coordinates because of the rejection of bins during averaging in either the PR or the GR.
The data are stratified into two regions-altitudes less than $4 \mathrm{~km}$ and greater than $4 \mathrm{~km}$-and the reflectivity comparison are performed for these two regions (the $D_{o}$ and the rainfall estimates are analyzed only for the

TABLE 1. TC and non-TC overpass events and their corresponding TRMM orbit number. The events are arranged with respect to the percentage of convective activity, given in the last column.

\begin{tabular}{rlcc}
\hline \hline No. & Event & TRMM orbit & Convection \\
\hline 1 & 17 Jan 2012 & 80728 & 0 \\
2 & 17 Nov 2011 & 79773 & 2.1 \\
3 & 27 Feb 2012 & 81369 & 3.2 \\
4 & 10 Mar 2012 & 81559 & 6.7 \\
5 & 14 Feb 2011 & 75484 & 9.8 \\
6 & 13 Jan 2012 & 80667 & 10.8 \\
7 & 17 Feb 2011 & 75523 & 14.1 \\
8 & 13 Mar 2012 & 81598 & 16.0 \\
9 & 18 Jan 2012 & 80750 & 35.6 \\
10 & 21 Jan 2012 & 80789 & 46.3 \\
11 & 20 Nov 2011 & 79819 & 68.6 \\
12 & 25 Jan 2012 & 80850 & 79.1 \\
13 & 9 Nov 2011 & 79651 & 80.0 \\
\hline
\end{tabular}


GR Reflectivity
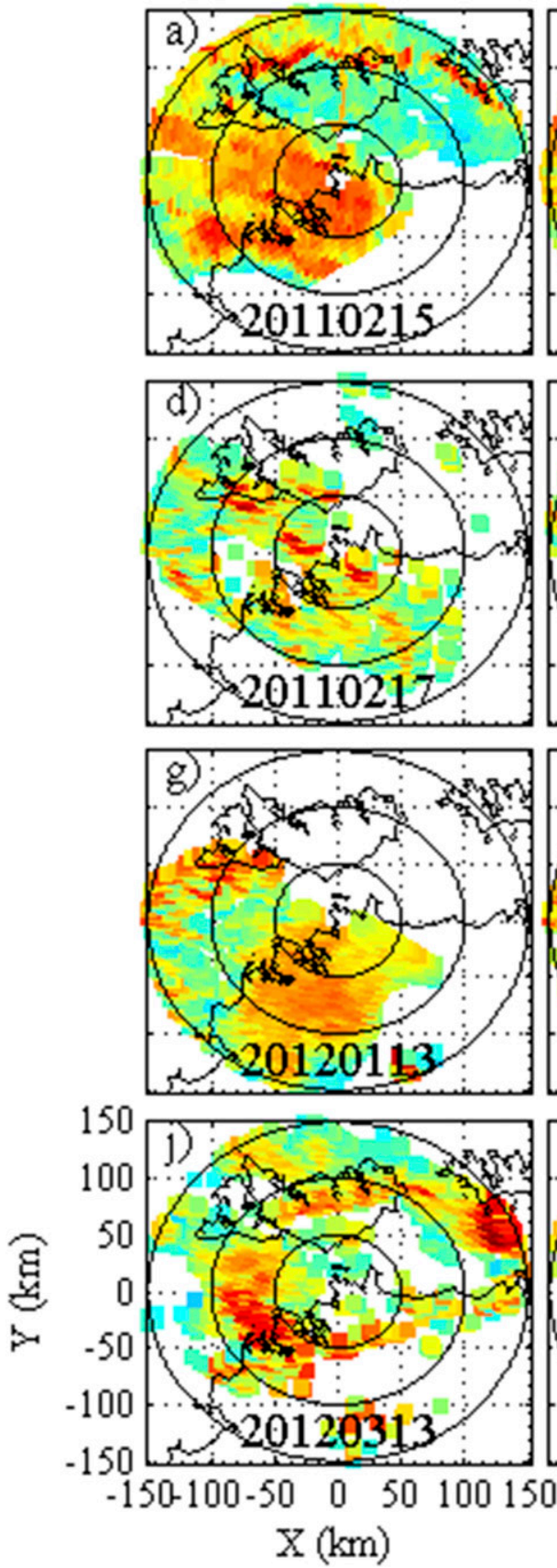

PR Reflectivity
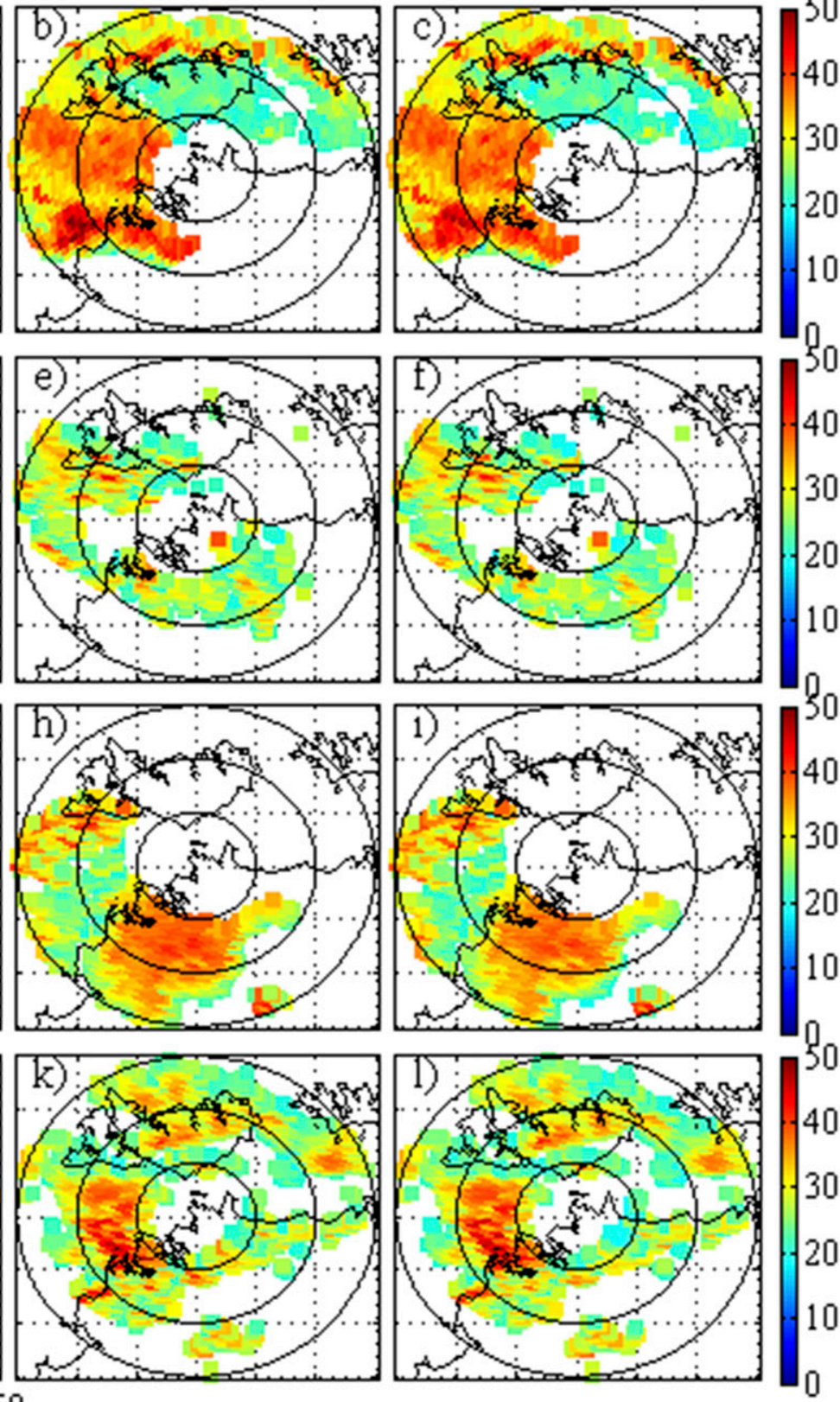

COM Reflectivity
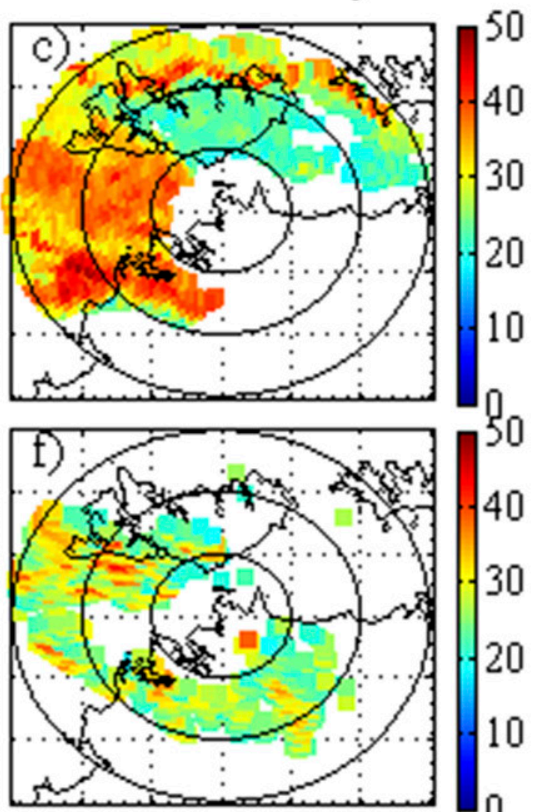

$-40$

30

20

10
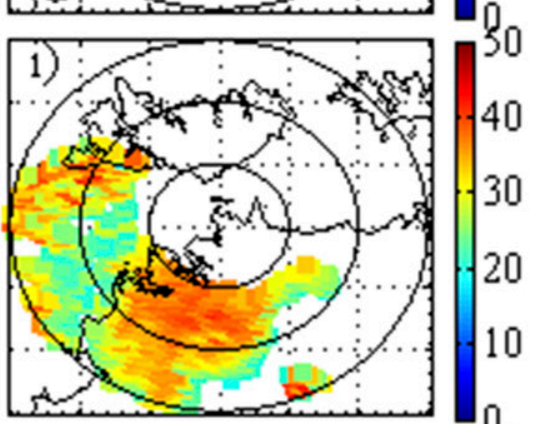

40

30

20

10
40

30

20

FIG. 3. Matched reflectivity profiles ( $\mathrm{dB} Z$ ) from the (left) GR, (middle) PR, and (right) COM for the events shown in Fig. 2 at the $1.3^{\circ}$ GR elevation sweep.

former). This altitude roughly divides the liquid and frozen hydrometer regions. Regions below the $0^{\circ} \mathrm{C}$ isotherm, which is located at about $5 \mathrm{~km}$, are mostly dominated by liquid hydrometeors, and we have chosen less than $4 \mathrm{~km}$ to minimize the inclusion of frozen hydrometeors. At higher altitudes, frozen hydrometeors are more dominant. The melting layer is also at the $0^{\circ} \mathrm{C}$ isotherm, which is usually seen as a bright band in the radar signature.

The scatterplot in Fig. 4 shows the distribution of the reflectivity in the PR and the COM against the GR for the two TC and the two non-TC case events for elevations 

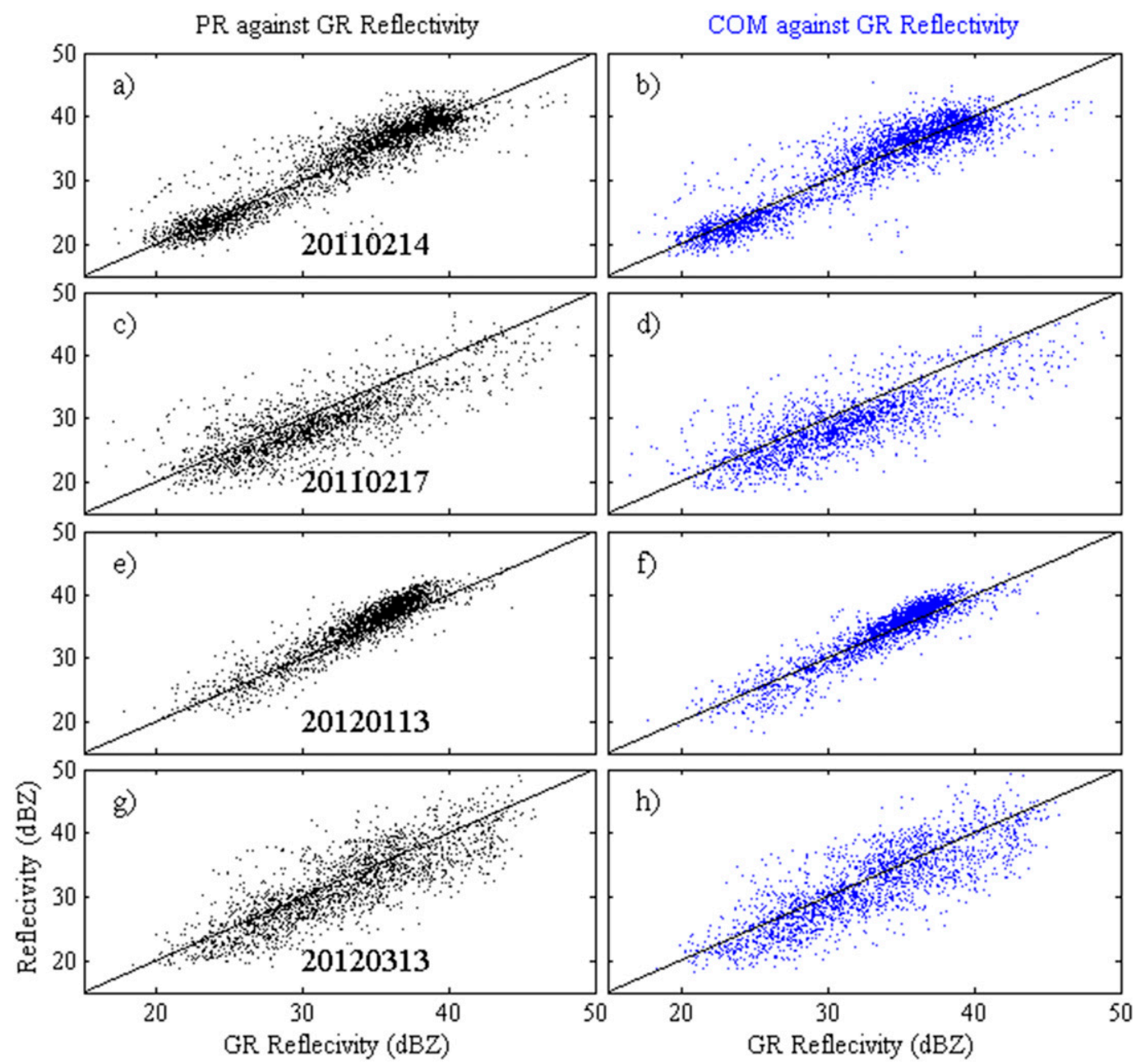

FIG. 4. Scatterplot of the matched reflectivity profiles (dBZ) for altitude less than $4 \mathrm{~km}$ from the (left) PR and (right) COM against the GR for the events shown in Fig. 2.

less than $4 \mathrm{~km}$. There is a strong positive linear association between TRMM and the GR for the four case events. The scatter difference, however, could be both small (as in non-TC event 1 ) and large (as in TC events 1 and 2 and in non-TC event 2).

The statistics are presented next. Figure 5 shows the $r$, RMSE, and bias for the four case events with rainfall of each event further separated into convective, stratiform, over the land, and over the ocean. Considering separation into rainfall types, it is evident that there is a larger degree of disagreement between the satellite estimates and the GR during convective rainfall than during stratiform rainfall. For example, the correlation in convective rainfall is consistently weaker than that in stratiform rainfall, and the RMSE and the bias are consistently larger for the convective group than for the stratiform group. Note that the deviation in the correlation and the bias between the convective and stratiform groups is much larger in TC event 1 (Figs. 5a and $5 \mathrm{c}$, respectively) than in the other events. The more positive bias during convective rainfall shows a somewhat greater degree of overestimation by the satellite estimates during such rainfall. This could largely be due to the nature of convective-type rainfall, which can be highly variable within the PR footprint and can rapidly change with time.

Considering terrain separation (over the ocean and the land), a clearly better performance of the PR over the ocean in comparison to that over the land is not evident. For example, events 1, 3, and 4 have a larger correlation and a smaller RMSE in the PR over the ocean than that over the land but for event 2 it is the opposite. Also, the bias for events 1 and 3 over the ocean is smaller than that over the land, whereas for events 2 and 4 it is the opposite. While this could roughly point to a better performance over the ocean, a further 

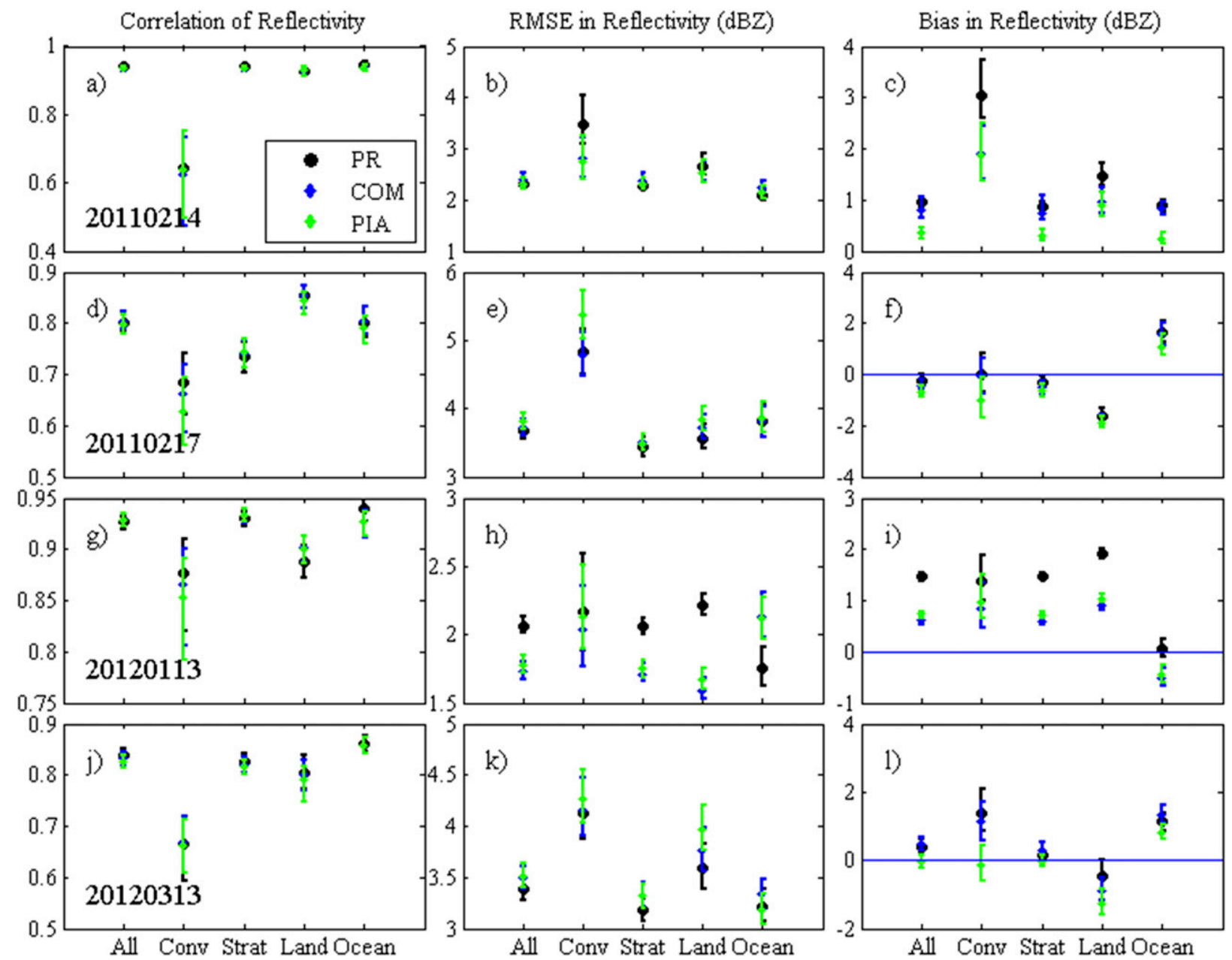

FIG. 5. Statistics of (left) $r$, (middle) RMSE, and (right) bias of the matched reflectivity profiles for the events shown in Fig. 2 for altitude less than $4 \mathrm{~km}$. Events have been further separated into convective (Conv), stratiform (Strat), over the land, and over the ocean. The error bars show the $95 \%$ confidence interval.

computation shows that the terrain separation results are also dependent on the rainfall type over the area: for events 1,3 , and 4 there is a greater percentage of convective rainfall over the land than over the ocean, whereas for event 2 it is the opposite. As discussed earlier, the performance is weaker when more convective rainfall is present.

Figure 6 shows the statistics for the matched reflectivity profiles of all the events (2 TC and 11 non-TC) for altitudes less than $4 \mathrm{~km}$. The events are arranged in the order of increasing percentage of convective rainfall, the values of which are shown in Fig. 6d. The $r$ (Fig. 6a) for the majority of the events (11 out of 13 events for both the PR and COM) is in between 0.6 and 1, which shows a reasonable correlation between the spaceborne instruments and the DARW GR. Also, for most of the events, there is marginal to no difference in the $r$ between the PR, the COM, and the PIA, which shows that the different spaceborne data have almost the same degree of linear association with the GR.

The RMSE (Fig. 6b) ranges from 1 to $7.56 \mathrm{dBZ}$ $(4.5 \%-16 \%)$, and for the majority of the events (11 out of 13) there is statistically no significant difference in the RMSE between the spaceborne measurements. However, there is a systematic increase in the error with an increase in the percentage of convection in the rainfall events.

The bias (Fig. 6c) is not that large; it ranges from -2.4 to $1.4 \mathrm{dBZ}(-5.75 \%$ to $+3.4 \%)$ and the bias in the COM and the PIA is either statistically the same or smaller than in the PR. Considering the degree of convective rainfall, the majority of the events (six out of eight) below the $20 \%$ level have a positive bias, whereas all the events (five) above the $20 \%$ level have a negative bias. This suggests that the spaceborne instruments could be mostly biased high during highly stratiform rainfall (or 
(a) Correlation of Reflectivity

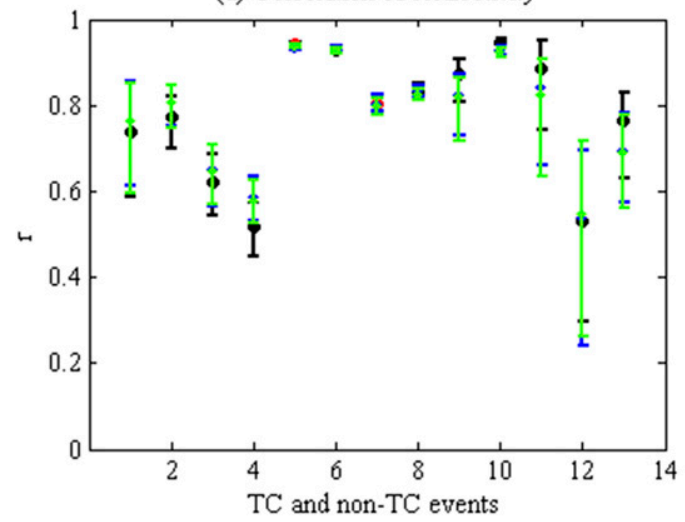

(c) Bias Reflectivity

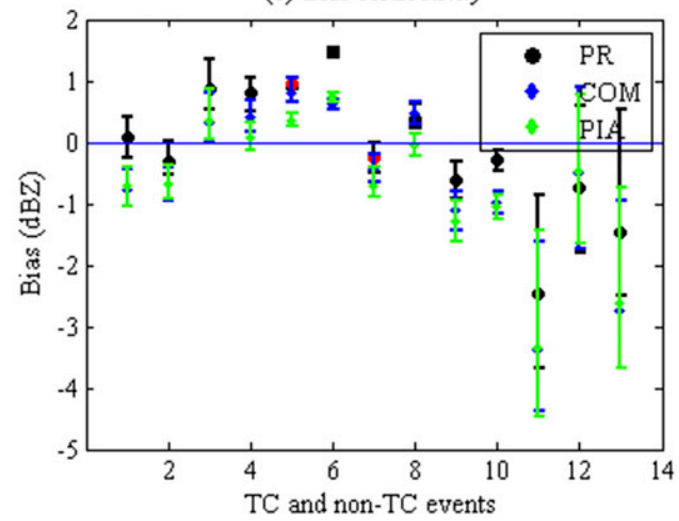

(b) RMSE Reflectivity

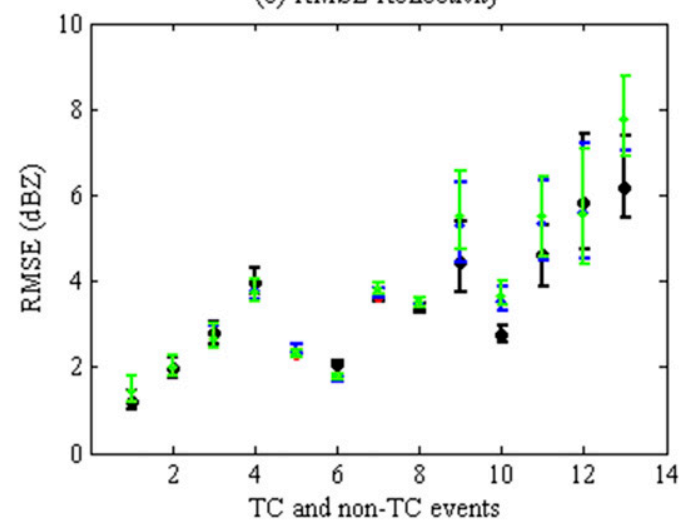

(d) GR Mean Reflectivity

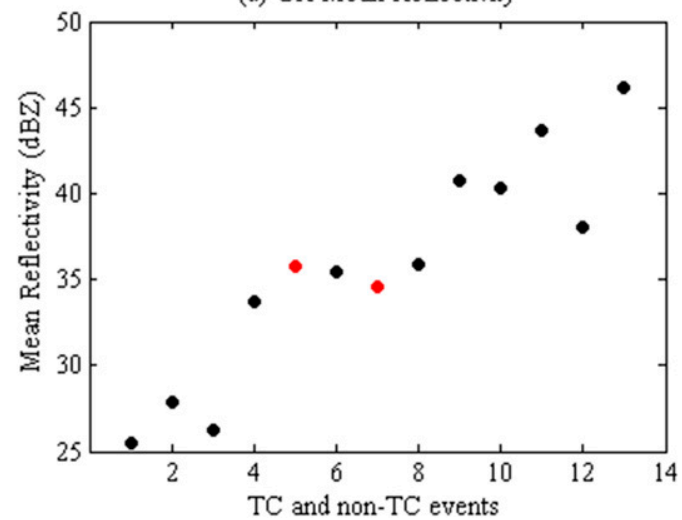

FIG. 6. Statistics of (a) $r$, (b) RMSE, and (c) bias for the TC and non-TC events for altitude less than $4 \mathrm{~km}$. (d) GR average reflectivity of each event. The TC events are marked as red [the first red point from the left (event 5) is the 15 Feb 2011 event and the second red point (event 7) is the 17 Feb 2011 event]. The error bars show the $95 \%$ confidence interval.

overestimating the reflectivity when considering the DARW GR as the reference) and they could be biased low during more convective rainfall (or for the case of DARW GR as the reference, they underestimate the reflectivity). Placing the TC events into context, it is evident that the association of the PR and the COM with the GR during the passage of TC Carlos is similar to that during the more stratiform rainfall events.

One of the factors that could lead to an error in the PR estimate is the nonuniform beamfilling (NUBF), which is the presence of nonuniformity in the reflectivity within a radar field of view. NUBF is corrected for in the $2 \mathrm{~A} 25 \mathrm{~V} 7$ algorithm but not in the COM and PIA algorithms. However, the NUBF correction requires an assumption of nonuniformity that can lead to overestimates if the assumed coefficient of variation is too high (Iguchi et al. 2009). This can explain the overestimation of PR relative to the COM and the PIA. It is also known that the PR suffers from significant attenuation, especially in convective rainfall, and an attenuation correction tends to perform quite well for convective rainfall but it slightly overcorrects for stratiform rainfall (Wang and Wolff 2009). This further explains the positive bias in the spaceborne instruments during highly stratiform rainfall and vice versa for highly convective rainfall events. The overestimation of the COM and the PIA relative to the GR can be possibly explained by attenuation of the C-band reflectivity that is not fully corrected by the Bringi et al. (2001) method. This is evident in the outer range rings of Fig. 3a, where a large positive difference between the PR (or the COM) reflectivity and the GR reflectivity exists at the $225^{\circ}$ azimuth. Since this difference is present even outside the convective cores, there should not be a large error in the PR attenuation correction, since there is not a significant attenuation along the PR line of sight in this situation. However, there is significant attenuation along the GR line of sight in this situation and small underestimates in the attenuation correction can lead to these biases (Fig. 7). 

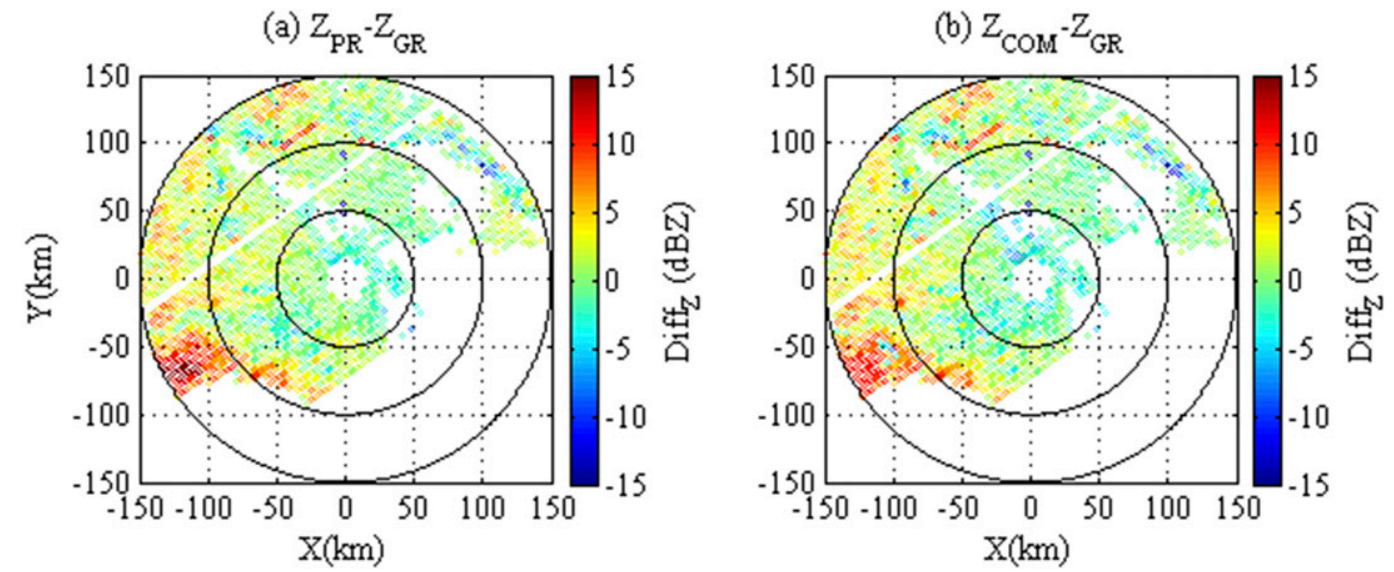

FIG. 7. Reflectivity difference with respect to the GR at 3-km altitude (a) for the PR and (b) for the COM for TC 1 (14 Feb 2011).

The statistics for reflectivities measured at altitudes greater than $4 \mathrm{~km}$ are also presented (shown in Fig. 8). These are for 11 events, as 2 events have a small sample (less than 10) above the 4-km level. While the linear association $(r)$ is almost the same as that for the lessthan-4-km group, there are some notable differences in the other statistics. First, the error (RMSE) increases for the majority (nine) of the events (the RMSE for the different spaceborne measurements are almost the same). Second, the bias of the greater-than-4-km group is less than that of the less-than-4-km group for almost all of the events (the difference is in the range -5.17 to (a) Correlation of Reflectivity

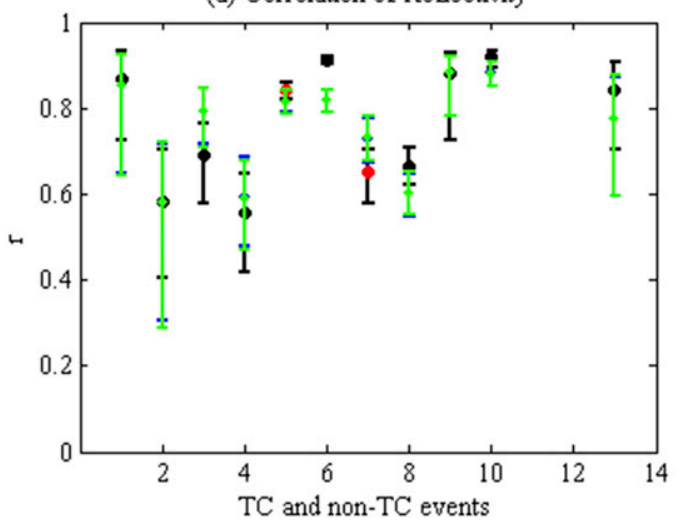

(c) Bias Reflectivity

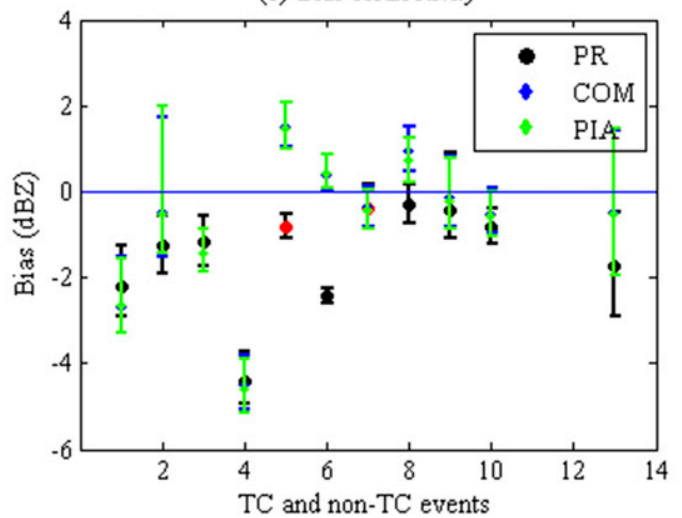

(b) RMSE Reflectivity

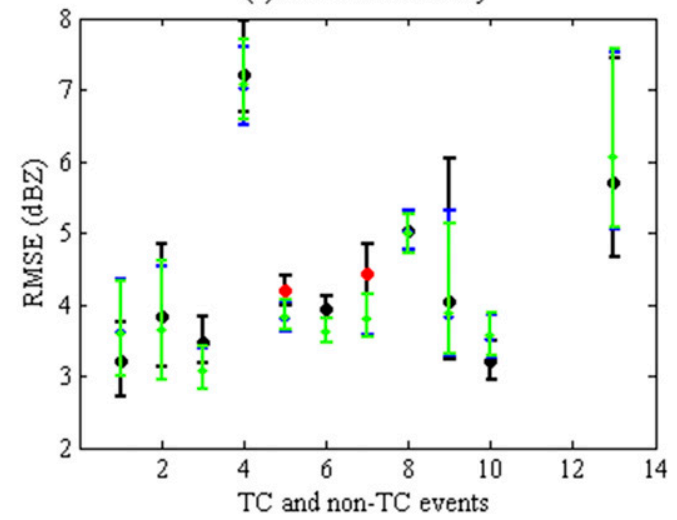

(d) GR Mean Reflectivity

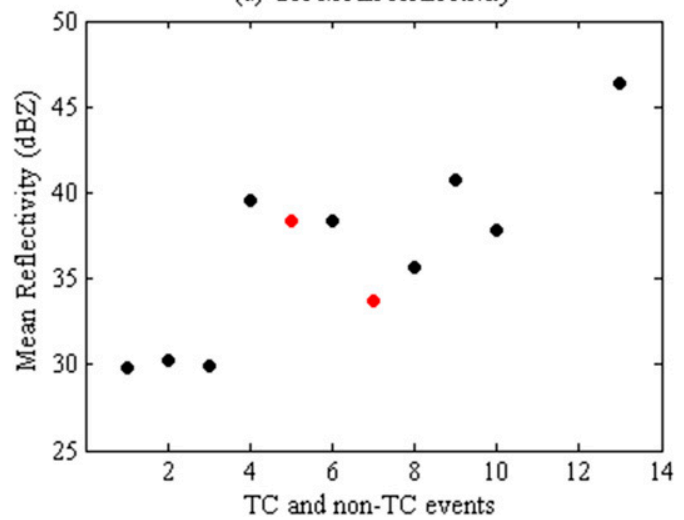

FIG. 8. As in Fig. 6, but for altitude greater than $4 \mathrm{~km}$. 

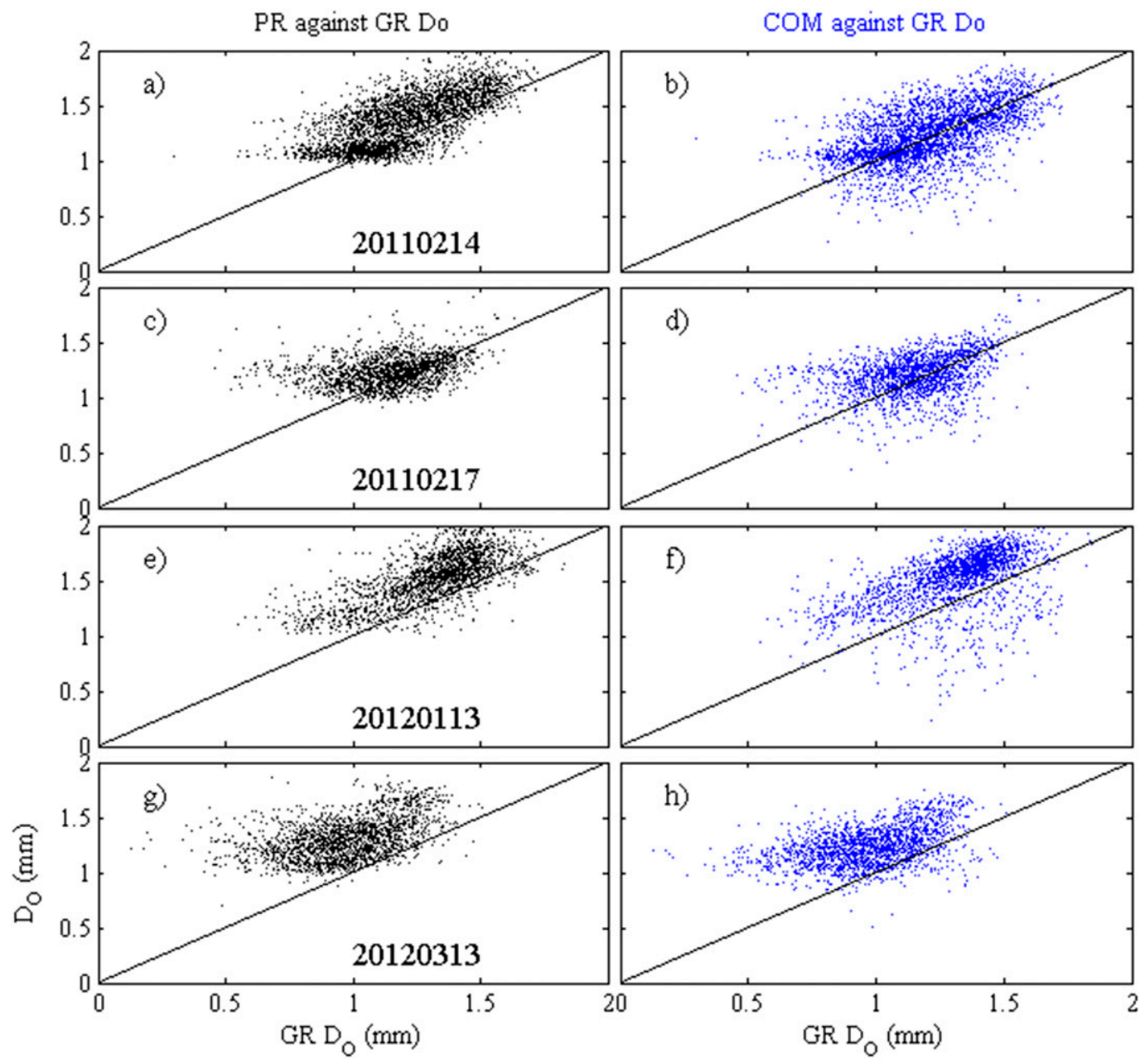

FIG. 9. As in Fig. 4, but for $D_{o}$.

$0.23 \mathrm{dBZ}$ ) and the difference is larger in the events with a larger percentage of stratiform rather than convective rainfall. The bias for the different spaceborne measurements is the same for most of the events except for event 5 (which is TC event 1 ) and for event 6 , where the bias in the COM and the PIA is larger than that in the PR.

The results obtained here for the reflectivity comparison are consistent with most of the studies over other regions (Kim et al. 2014; Liao and Meneghini 2009; Park et al. 2015; Schwaller and Morris 2011). For example, Park et al. (2015) show that for elevations less than $4 \mathrm{~km}$, the bias for widespread events is small with a slight overestimation by the PR (less than $1 \mathrm{dBZ}$ ), whereas for convective cases the bias is negative (greater than $-4 \mathrm{dBZ}$ ) and the RMSE is larger than that in widespread cases, as also reported here. The usually negative bias for the more convective events suggests greater attenuation at the PR frequency than the GR frequency and the larger RMSE could be due to the nature of convective storms (a greater degree of small-scale spatial variability). Another contributing factor could be NUBF for small-scale events. Park et al. (2015) also show that for elevations greater than $4 \mathrm{~km}$, the bias becomes negative (1-3dBZ smaller in the PR than in the GR) and the RMSE increases in the widespread events, whereas there is not much variation for convective events as reported here. Such differences are attributed to a mismatch in the brightband height, and the scattering differences in the PR and the GR for mixed-phase hydrometeors in and above the melting layer (Park et al. (2015) and the references therein). In addition, hydrometeors in stratiform events are mainly dry snow that gives weak radar returns. Hence, a PR sensitivity of $18 \mathrm{dBZ}$ may be another contribution to the negative bias (shown in Fig. 8c).

\section{c. Comparison of $D_{o}$}

The consistency of the aforementioned results with other studies provides the impetus to examine the $D_{o}$ 

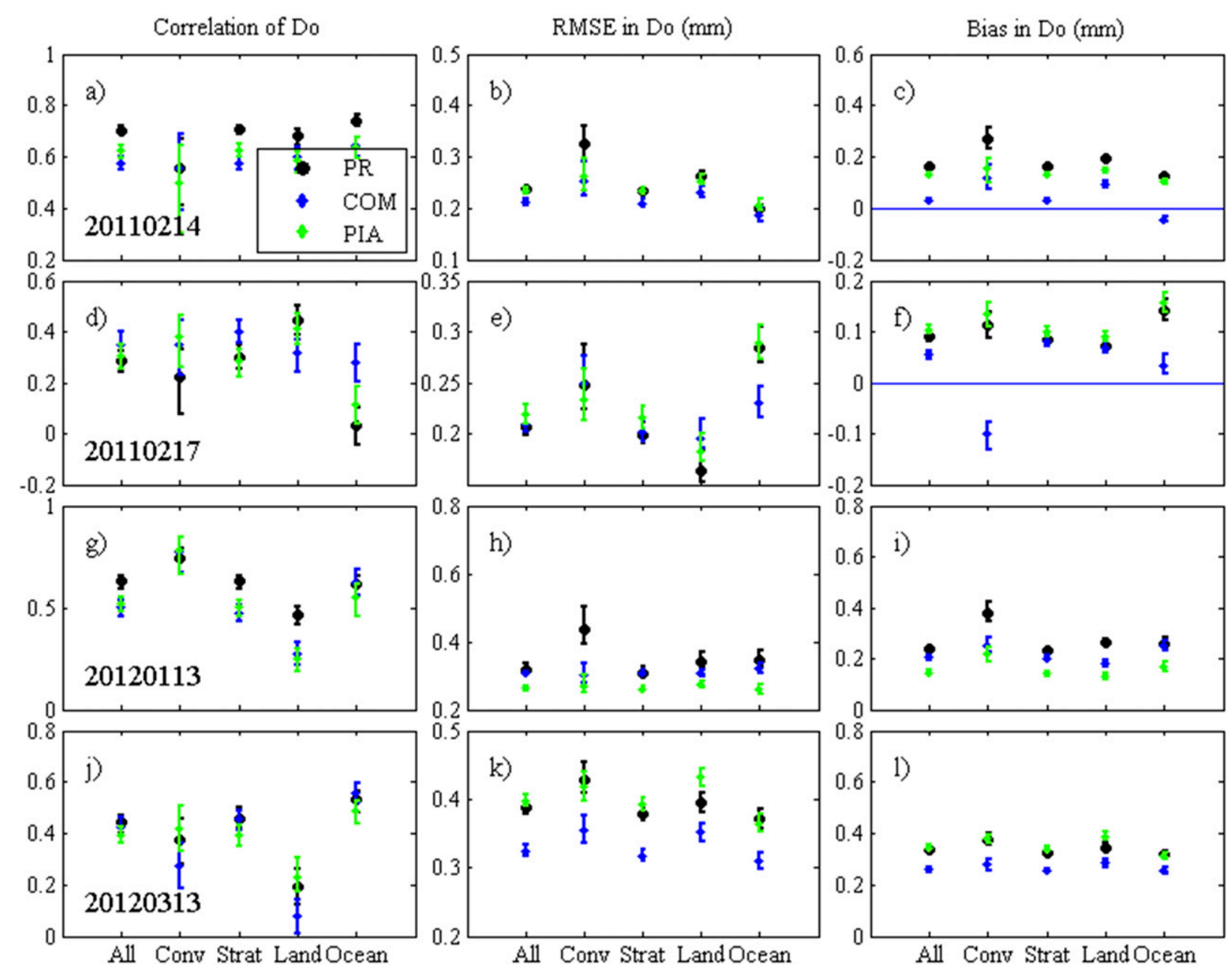

FIG. 10. As in Fig. 5, but for $D_{o}$.

and the rainfall estimates. The $D_{o}$ estimates for the rainfall region (altitudes less than $4 \mathrm{~km}$ ) are presented next. Figure 9 shows the corresponding scatterplots of $D_{o}$ for the two TC and the two non-TC case events (shown in Fig. 2). A positive linear association between the PR (or the COM) and the GR is evident but the association is weak, particularly at smaller $D_{o}$ values. Unlike the two TC events, the scatter for the two non-TC events is mostly above the line of perfect agreement. Also, the $D_{o}$ in the PR is greater than $1 \mathrm{~mm}$, whereas in the COM and in the GR there are values less than $1 \mathrm{~mm}$.

Figure 10 shows the $D_{o}$ statistics for the two TC and the two non-TC case events with further separation into rainfall and terrain types. Similar to the reflectivity estimates, it is evident that there is a larger degree of disagreement between the satellite estimates and the GR during convective rainfall than during stratiform rainfall. For the PR, the $r$ of the convective group is weaker than that of the stratiform group (except for event 3 ), whereas the RMSE and the bias for the convective group are consistently larger than that for the stratiform group. For separation into terrain types, the results are similar to that obtained for the reflectivity estimates whereby the PR has a larger deviation over the land for events 1,3 , and 4 in comparison to event 2 .

Figure 11 shows the statistics for the matched $D_{o}$ profiles of all the events ( $2 \mathrm{TC}$ and 11 non-TC) in the rainfall region. The linear association ( $r$; Fig. 11a) between the spaceborne instruments and the GR is generally not strong. Also, the RMSE (Fig. 11b) is larger for the more convective events, which shows more variability between the spaceborne and the GR $D_{o}$ as events become more convective.

A similar trend is also observed in the bias (Fig. 11c), where it increases with an increase in the convection; the bias ranges from -0.08 to $0.57 \mathrm{~mm}$ (or $-6 \%$ to $58 \%$ ) in 
(a) Correlation of Do

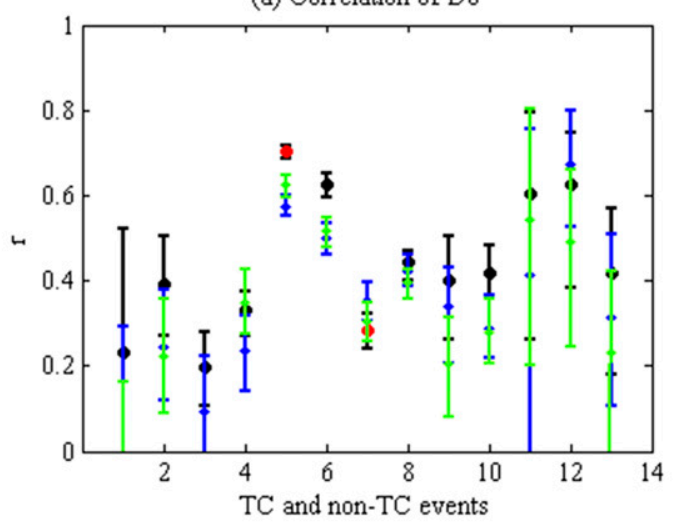

(c) Bias Do

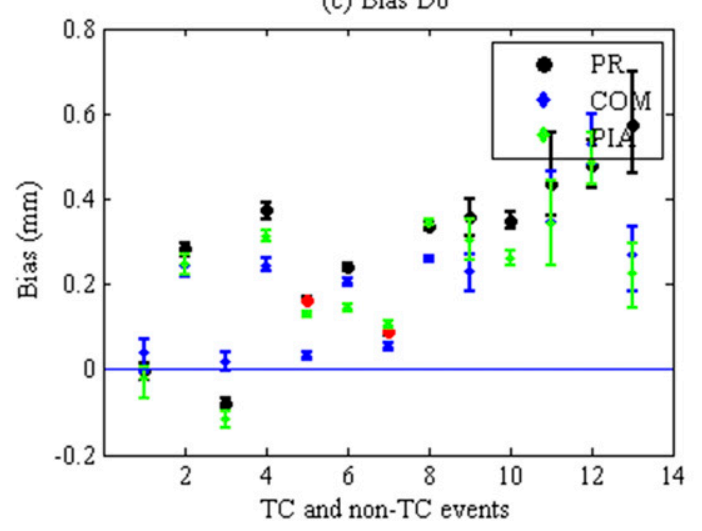

(b) RMSE Do

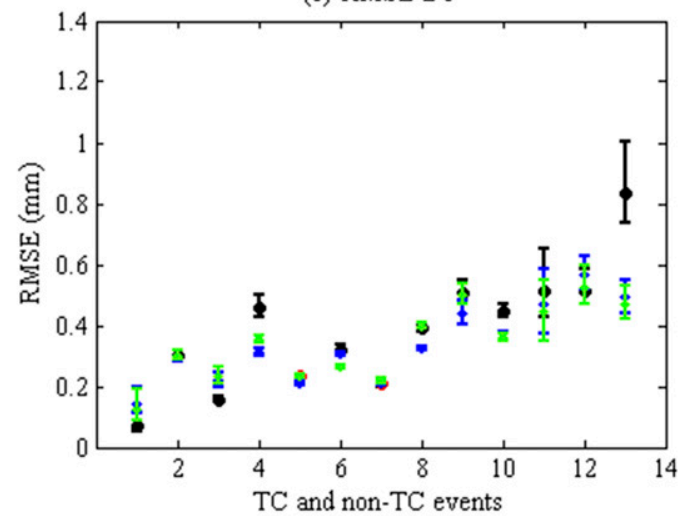

(d) GR Mean Do

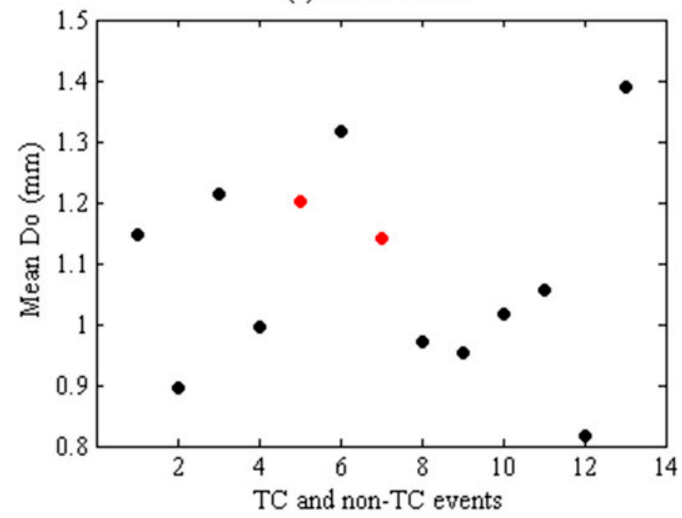

FIG. 11. As in Fig. 6, but for $D_{o}$.

the PR. Also, for the majority of the events, the bias is positive both in the PR and the COM, which shows that TRMM tends to mostly overestimate the $D_{o}$ with respect to the DARW GR. However, the bias in the COM appears to be smaller than that in the PR, especially for the majority of the less convective events (i.e., events with less than $20 \%$ convection). Moreover, it could be concluded that the association of the PR and the COM $D_{o}$ estimates with the GR during the passage of TC Carlos is similar to that during the more stratiform rainfall events (congruent with the results obtained for the reflectivity estimates).

The results obtained here for the PR and the COM $D_{o}$ are consistent with Bringi et al. (2012), who found that the PR overestimates the $D_{o}$ with respect to the KWAJ GR for the two cases they examined (the bias ranged from $11.7 \%$ to $24.6 \%$ ). They also show that the bias in the COM is smaller than that in the PR $(-0.8 \%$ to $9.7 \%)$. We note that in most cases in Fig. 11c, the biases of PR and the PIA algorithm are similar to each other, but the COM algorithm can differ and is often closer to zero, particularly in the cases with low convective fraction. This suggests that the addition of measurements from TMI, specifically the strong positive relationship between liquid water path and brightness temperature over water surfaces, is providing information that adjusts the DSD in rainfall over ocean that is not present in the radar-only algorithms, which rely on the default stratiform and convective DSD assumption in profiles without significant attenuation (Kozu et al. 2009).

\section{d. Comparison of rainfall rate}

Finally, we compare the rainfall rates estimated from the spaceborne instruments and the GR. These are performed for altitudes less than $4 \mathrm{~km}$. Figure 12 shows the scatterplots of the rainfall rate from the PR and the COM against the GR for the four case events. Both the $\mathrm{PR}$ and the COM have a positive linear relationship with the GR but the data points deviate considerably from the line of perfect agreement, especially for events 1,2 , and 4 .

The statistics for the case events, including separation into rainfall and terrain types, are presented in Fig. 13. It is evident that there is a larger degree of overestimation by the PR during convective rainfall 

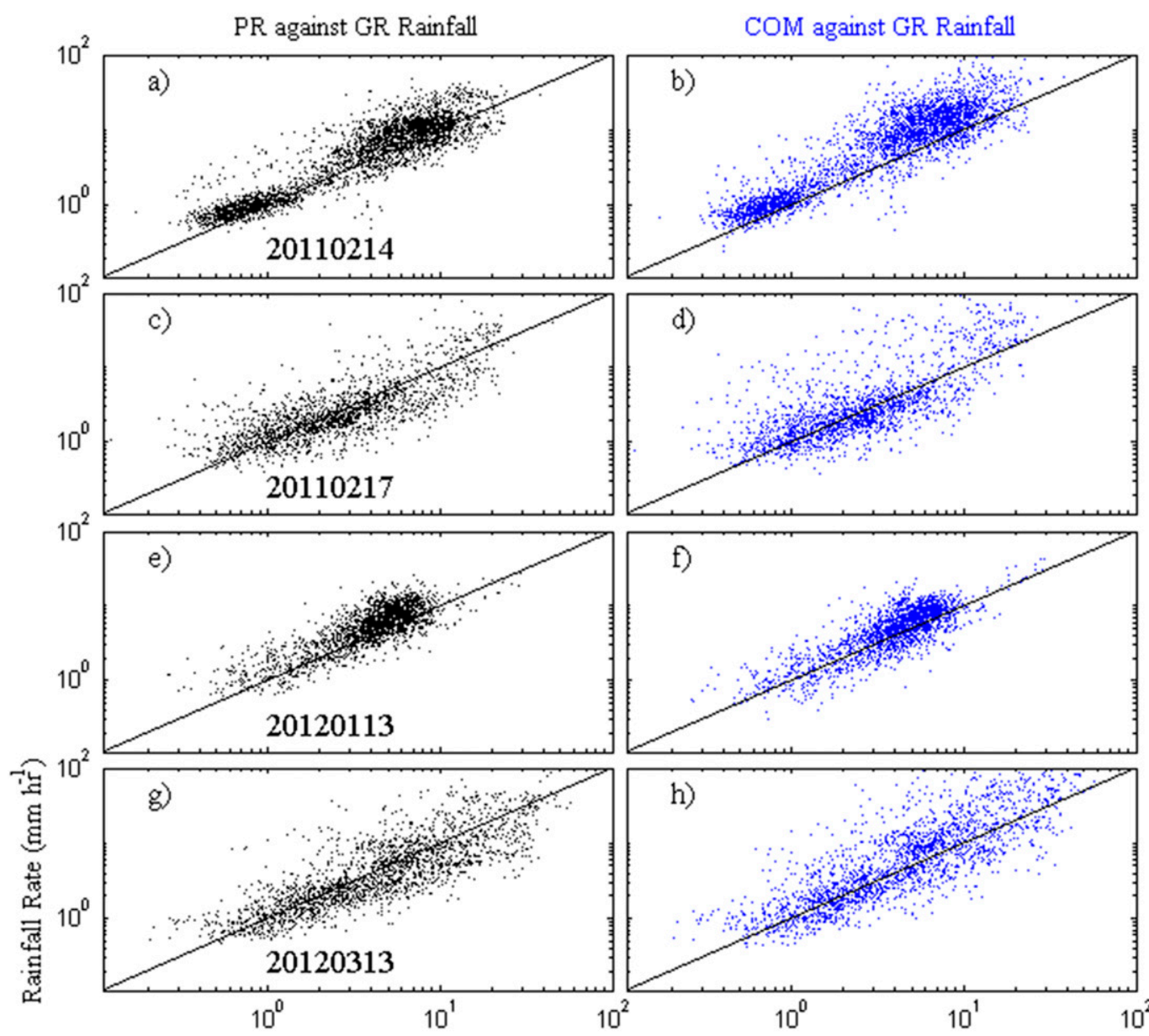

GR Rainfall Rate $\left(\mathrm{mm} \mathrm{hr}^{-1}\right)$

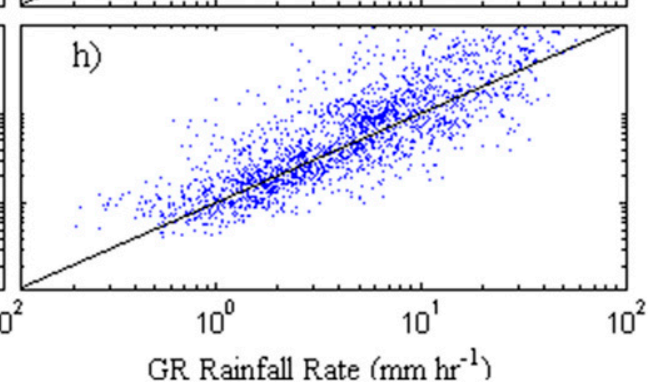

FIG. 12. As in Figs. 4 and 9, but for rainfall rate.

than during stratiform rainfall for the two TC events (for the two non-TC events the results are mixed). This follows the clear larger overestimation of reflectivity estimates during convective than during stratiform rainfall for the two TC events (Figs. 5c and 5f). However, the COM consistently has a larger degree of overestimation for the convective group for both the TC and non-TC events. For separation into terrain types, a clear pattern is not evident.

Figure 14 shows the statistics for the rainfall profiles of all the events (2 TC and 11 non-TC). The correlation (Fig. 14a) of the PR and the COM with the GR for most of the events (11) is greater than 0.5 and it is the same for both the instruments. The correlation, nonetheless, decreases with an increase in the percentage of convection.

Consequently, the RMSE tends to increase with an increase in the percentage of convection, which is more evident in the PR. For the greater stratiform events (below $20 \%$ convection), the COM has a similar RMSE as the PR for events 1-3 (the RMSE for these events is also small) but for events $4-8$ the COM generally has a larger RMSE than the PR. For the more convective events (greater than $20 \%$ convection), a statistically significant difference in the error between the PR and the COM is not evident for most of the events.

The bias is shown in Fig. 14c and some important conclusions are as follows. The bias decreases (becomes more negative) with an increase in the percentage of convection and this trend is prominent in both the PR and the COM. For the highly stratiform rainfall events, there is a mixture of a good match and overestimation with respect to the GR. For the highly convective events, the spaceborne instruments generally underestimate the rainfall observed by the GR. Also, the bias in the COM is greater than that in the PR for more than $50 \%$ of the events. 

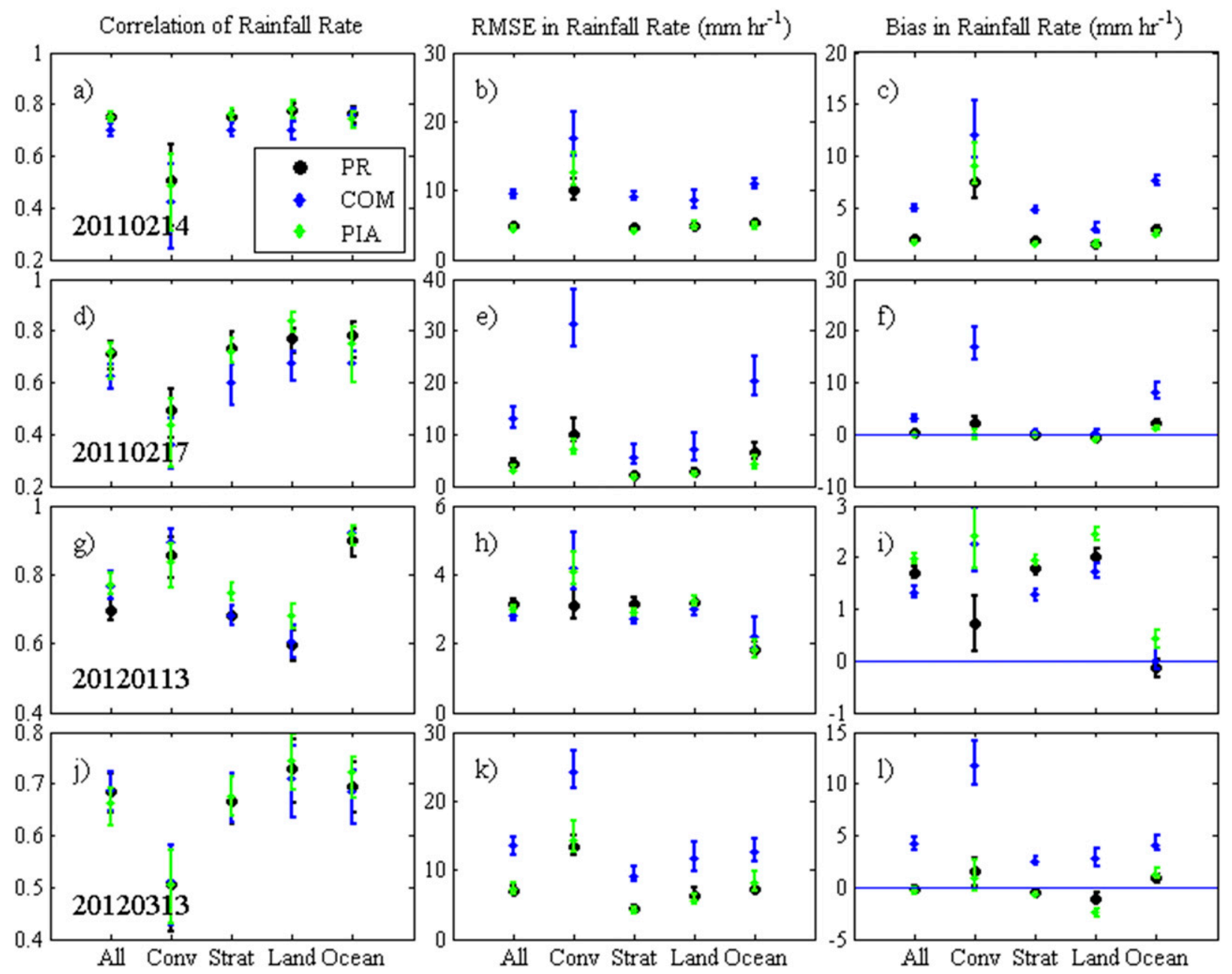

FIG. 13. As in Figs. 5 and 10, but for rainfall.

This is somewhat similar to the results obtained by Bringi et al. (2012), who report an increase in the bias in the COM rainfall with respect to the KWAJ GR. The biases they report are, however, negative in both the PR and the COM. The bias of the COM algorithm relative to the PIA and PR algorithms can also be explained in the context of the reflectivity and $D_{o}$ biases. In the events with significant positive bias, the reflectivity bias (relative to GR) is also positive but the $D_{o}$ bias, while positive, is less strongly positive than PR and PIA algorithms. The combination of high reflectivity and smaller $D_{o}$ must result in a positive rainfall bias. Other possibilities could be (i) the NUBF correction is too much, (ii) the vertical hydrometeor phase is incorrect, or (iii) the GR $D_{o}$ is too low as a result of an insufficient attenuation correction of the $Z_{\mathrm{dr}}$. Furthermore, the rainfall statistics are dominated by the highest rates when compared to the $Z$ and $D_{o}$ statistics (Figs. 6 and 10), which are more normally distributed and thus have even contribution from light and moderate rates.

Comparing the results obtained here with studies over other regions, especially for the PR, show mixed results. Table 2 shows a list of some of these studies and the corresponding biases between the PR and GR estimates of rainfall. It is evident that there is a mixture of overestimation and underestimation of the rainfall by the PR over the different regions. Nonetheless, the study here shows some clear pattern as discussed above. The results here are also congruent with the findings of Kirstetter et al. (2013). For example, their correlation coefficient of 0.68 between PR and GR rainfall estimates agrees well and using an error model they show that the bias and the RMSE in $R$ increases as the convective part increases (i.e., more underestimation of $R$ and an increase in RMSE). They further quantified the error sources in PR rainfall estimates, like rainfall type classification and NUBF, and 
(a) Correlation of Rainfall

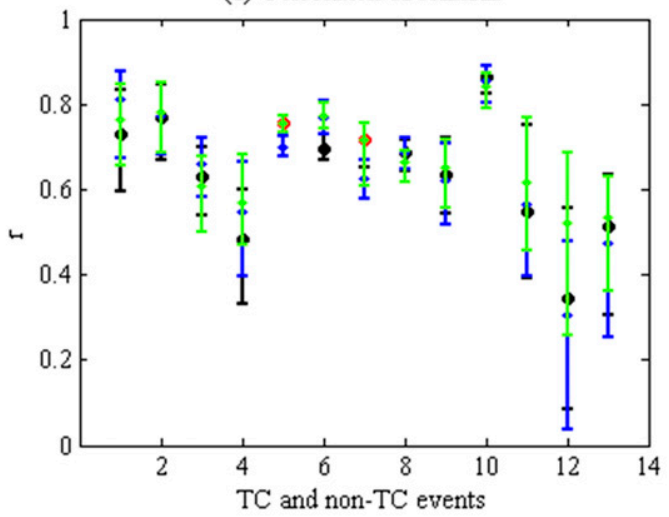

(c) Bias Rainfall

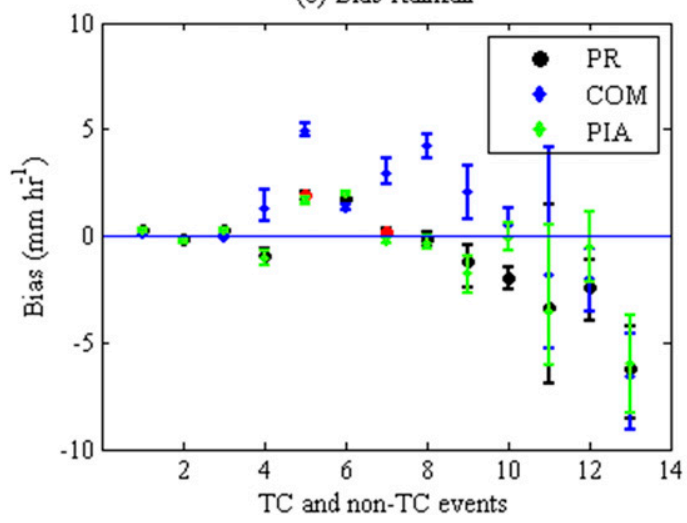

(b) RMSE Rainfall

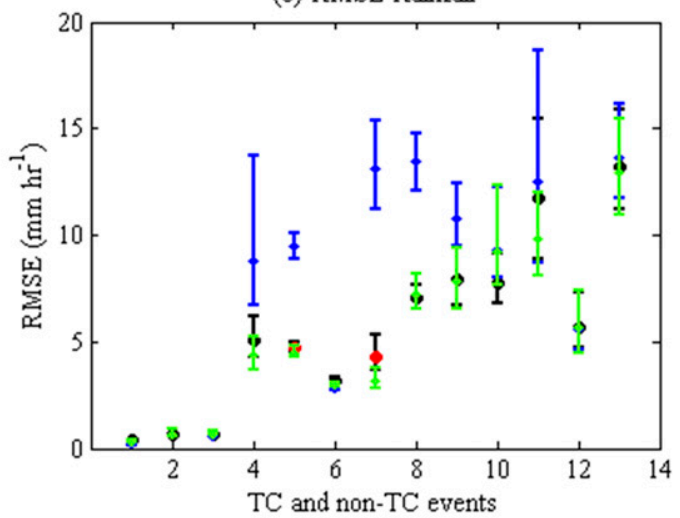

(d) GR Mean Rainfall

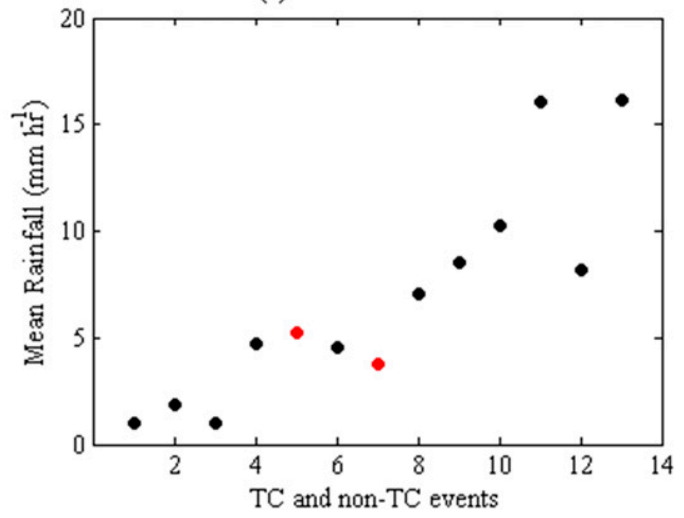

FIG. 14. As in Figs. 6 and 11, but for rainfall rate.

showed that the overestimation at lighter rain rates mainly comes from the convective $Z-R$ relationship and that the underestimation at high rain rates is related to NUBF effects.

\section{Summary}

In this study we use $2 \mathrm{TC}$ and 11 non-TC rainfall events to compare the reflectivity, the median volume diameter $D_{o}$, and rainfall rates estimated using the TRMM PR $(2 \mathrm{~A} 25, \mathrm{~V} 7)$, the combined algorithm (COM) developed by Munchak and Kummerow (2011), and the DARW GR, which is one of the TRMM ground validation sites. This is the first study that cross validates the PR and the COM-derived DSD and rainfall rates against a GR during the passage of TCs. The cross validation of the PR and the COM over Darwin, Australia, and the use of several non-TC events for a comparative study are some of the other originalities of this research.

The correspondence of the spaceborne instruments (i.e., the PR and the COM) with the DARW GR, taken as the reference, is shown to be largely dependent on the percentage of convection in the rainfall event.
Moreover, putting the two TC events into context, which are highly stratiform in nature, the association of the TRMM estimates with the GR for these two events is similar to that observed for the highly stratiform non-TC events (there is no significant difference) but it differs considerably from that observed for the majority of the highly convective non-TC events.

The PR and the COM mostly overestimate the reflectivities of events with a greater percentage of stratiform rainfall, and they mostly underestimate the reflectivities as events become more convective. Moreover, the bias in the COM is either the same or smaller than that in the PR, which could be a positive result of blending the TRMM microwave estimates with the PR.

Considering the $D_{o}$ estimates, the linear association between the spaceborne instruments and the GR is shown to be weak. Moreover, the PR and the COM overestimate the $D_{o}$ for most of the events and the magnitude of overestimation increases as the events become more convective. Also, the bias in the COM is the same as that in the PR for the majority of the highly convective events, but it is generally smaller in the COM for the highly stratiform events. This shows that combining the TMI with the PR 
TABLE 2. PR and GR rainfall rate comparison from previous studies. The $2 \mathrm{~A} 25$ version used by the respective studies is also shown in the bias column.

\begin{tabular}{|c|c|c|c|}
\hline Region & Study by & Bias (\% of mean) & Rainfall/terrain \\
\hline \multirow[t]{2}{*}{ Korea } & Kim et al. (2014) & +16-80 (V6) & Stratiform \\
\hline & & +26-150 (V6) & Convective \\
\hline \multirow[t]{2}{*}{ KWAJ } & Wolff et al. (2005) & $+6(\mathrm{~V} 6)$ & - \\
\hline & Wolff and Fisher (2008) & $-13.7(\mathrm{~V} 6)$ & Ocean \\
\hline \multirow[t]{5}{*}{ MELB } & Wolff et al. (2005) & $-9.1(\mathrm{~V} 6)$ & - \\
\hline & Wolff and Fisher (2008) & $+4.1(\mathrm{~V} 6)$ & Ocean \\
\hline & & $+7(+8)(\mathrm{V} 6)$ & Land (coast) \\
\hline & Liao and Meneghini (2009) & $+9(\mathrm{~V} 6)$ & Stratiform \\
\hline & & -19 (V6) & Convective \\
\hline \multirow[t]{2}{*}{ Southern United States } & Kirstetter et al. (2013) & $-18(\mathrm{~V} 7)$ & Land \\
\hline & & $-23(\mathrm{~V} 6)$ & \\
\hline
\end{tabular}

improves the DSD retrieval in the highly stratiform events where the PR is less reliable.

Considering the rainfall estimates, the linear association and the bias between the spaceborne instruments and the GR decreases as events become more convective. For the highly stratiform rainfall events, there is a mixture of a good match and overestimation with respect to the GR. For the highly convective events, the spaceborne instruments generally underestimate the rainfall observed by the GR. Also, the bias in the COM is greater than in the PR for more than $50 \%$ of the events.

This cross-validation study gives some insight into the correspondence between the TRMM-based and the DARW GR-based estimates of rainfall characteristics during different rainfall regiments. TRMM could be used to characterize the DSD of TC rainfall events; however, its limitations need to be taken into consideration. For a more general conclusion, the study should be extended with more cases, especially during the passage of TCs, over a longer period of time and over different regions. It would also be worthwhile to further perform a similar cross validation of the rainfall characteristics estimated using the Global Precipitation Measurement (GPM; Hou et al. 2014)-based Dual-Frequency Precipitation Radar (DPR) with more TC rainfall events.

Acknowledgments. The authors thank the Australian Research Council Centre of Excellence for Climate System Science and their respective institutions for supporting this work and for funding Anil Deo's visit to the NASA Goddard Space Flight Center Mesoscale Atmospheric Processes Laboratory. The authors also thank Dr. Michael Whimpey, Dr. Alain Protat, and Dr. Valentin Louf of the Australian Bureau of Meteorology and Dr. Robert Warren of Monash University, Australia, for providing assistance with the data and the rainfall retrieval algorithms of the Darwin radar. Anil Deo also acknowledges the Australian government-sponsored Endeavour Postgraduate
Award for funding his doctorate degree at the University of Melbourne. The radar dataset was created by Valentin Louf as part of the U.S. Department of Energy ASR Program (DE-SC0014063), and support for this publication was provided through the NASA Precipitation Measurement Missions Science Team under Program Manager Dr. Gail Skofronick-Jackson.

\section{REFERENCES}

Atlas, D., C. W. Ulbrich, F. D. Marks, E. Amitai, and C. R. Williams, 1999: Systematic variation of drop size and radarrainfall relations. J. Geophys. Res., 104, 6155, https://doi.org/ 10.1029/1998JD200098.

Bolen, S. M., and V. Chandrasekar, 2000: Quantitative cross validation of space-based and ground-based radar observations. J. Appl. Meteor., 39, 2071-2079, https://doi.org/10.1175/15200450(2001)040<2071:QCVOSB > 2.0.CO;2.

$\longrightarrow$, and - 2003: Methodology for aligning and comparing spaceborne radar and ground-based radar observations. J. Atmos. Oceanic Technol., 20, 647-659, https://doi.org/10.1175/ 1520-0426(2003)20<647:MFAACS > 2.0.CO;2.

Bringi, V. N., T. D. Keenan, and V. Chandrasekar, 2001: Correcting C-band radar reflectivity and differential reflectivity data for rain attenuation: A self-consistent method with constraints. IEEE Trans. Geosci. Remote Sens., 39, 1906-1915, https://doi.org/10.1109/36.951081.

— C. R. Williams, M. Thurai, and P. T. May, 2009: Using dualpolarized radar and dual-frequency profiler for DSD characterization: A case study from Darwin, Australia. J. Atmos. Oceanic Technol., 26, 2107-2122, https://doi.org/10.1175/ 2009JTECHA1258.1.

- G.-J. Huang, S. J. Munchak, C. D. Kummerow, D. A. Marks, and D. B. Wolff, 2012: Comparison of drop size distribution parameter (D0) and rain rate from S-band dual-polarized ground radar, TRMM Precipitation Radar (PR), and combined PR-TMI: Two events from Kwajalein Atoll. J. Atmos. Oceanic Technol., 29 , 1603-1616, https://doi.org/10.1175/JTECH-D-11-00153.1.

Chandrasekar, V., S. M. Bolen, and E. Gorgucci, 2003a: Microphysical cross validation of spaceborne radar and ground polarimetric radar. IEEE Trans. Geosci. Remote Sens., 41, 2153-2165, https://doi.org/10.1109/TGRS.2003.817186.

$\ldots$, K. Mubarak, and S. Lim, 2003b: Estimation of raindrop size distribution from TRMM precipitation radar observations. 
IGARSS 2003: 2003 IEEE International Geoscience and Remote Sensing Symposium Proceedings; Learning from Earth's Shapes and Sizes, Vol. 3, IEEE, 1712-1714, https://doi.org/ 10.1109/IGARSS.2003.1294226.

_ _ L. Wanyu, and B. Zafar, 2005: Estimation of raindrop size distribution from spaceborne radar observations. IEEE Trans. Geosci. Remote Sens., 43, 1078-1086, https://doi.org/10.1109/ TGRS.2005.846130.

Deo, A., and K. J. E. Walsh, 2016: Contrasting tropical cyclone and non-tropical cyclone related rainfall drop size distribution at Darwin, Australia. Atmos. Res., 181, 81-94, https://doi.org/ 10.1016/j.atmosres.2016.06.015.

Efron, B., and R. J. Tibshirani, 1993: An Introduction to the Bootstrap. Chapman and Hall, $456 \mathrm{pp}$.

Grecu, M., W. S. Olson, S. J. Munchak, S. Ringerud, L. Liao, Z. Haddad, B. L. Kelley, and S. F. McLaughlin, 2016: The GPM combined algorithm. J. Atmos. Oceanic Technol., 33 2225-2245, https://doi.org/10.1175/JTECH-D-16-0019.1.

Hou, A. Y., and Coauthors, 2014: The Global Precipitation Measurement mission. Bull. Amer. Meteor. Soc., 95, 701-722, https://doi.org/10.1175/BAMS-D-13-00164.1.

Iguchi, T., T. Kozu, R. Meneghini, J. Awaka, and K. Okamoto, 2000: Rain-profiling algorithm for the TRMM Precipitation Radar. J. Appl. Meteor., 39, 2038-2052, https://doi.org/ 10.1175/1520-0450(2001)040<2038:RPAFTT > 2.0.CO;2.

— — J. Kwiatkowski, R. Meneghini, J. Awaka, and K. Okamoto, 2009: Uncertainties in the rain profiling algorithm for the TRMM Precipitation Radar. J. Meteor. Soc Japan, 87A, 1-30, https://doi.org/10.2151/jmsj.87A.1.

Keenan, T., K. Glasson, F. Cummings, T. S. Bird, J. Keeler, and J. Lutz, 1998: The BMRC/NCAR C-band polarimetric (C-POL) radar system. J. Atmos. Oceanic Technol., 15, 871-886, https://doi.org/ 10.1175/1520-0426(1998)015<0871:TBNCBP $>2.0 . C O ; 2$.

Kim, J.-H., M.-L. Ou, J.-D. Park, K. R. Morris, M. R. Schwaller, and D. B. Wolff, 2014: Global Precipitation Measurement (GPM) ground validation (GV) prototype in the Korean Peninsula. J. Atmos. Oceanic Technol., 31, 1902-1921, https:// doi.org/10.1175/JTECH-D-13-00193.1.

Kirstetter, P.-E., Y. Hong, J. J. Gourley, M. Schwaller, W. Petersen, and J. Zhang, 2013: Comparison of TRMM 2A25 products, version 6 and version 7, with NOAA/NSSL ground radarbased National Mosaic QPE. J. Hydrometeor., 14, 661-669, https://doi.org/10.1175/JHM-D-12-030.1.

Kozu, T., and Coauthors, 2001: Development of precipitation radar onboard the Tropical Rainfall Measuring Mission (TRMM) satellite. IEEE Trans. Geosci. Remote Sens., 39, 102-116, https://doi.org/10.1109/36.898669.

- T. Iguchi, T. Kubota, N. Yoshida, S. Seto, J. Kwiatkowski, and Y. N. Takayabu, 2009: Feasibility of raindrop size distribution parameter estimation with TRMM Precipitation Radar. J. Meteor. Japan, 87A, 53-66, https://doi.org/10.2151/jmsj.87A.53.

Kummerow, C., 1993: On the accuracy of the Eddington approximation for radiative transfer in the microwave frequencies. J. Geophys. Res., 98, 2757-2765, https://doi.org/10.1029/ 92JD02472.

Li, N., Z. Wang, F. Xu, Z. Chu, Y. Zhu, and J. Han, 2017: The assessment of ground-based weather radar data by comparison with TRMM PR. IEEE Geosci. Remote Sens. Lett., 14, 7276, https://doi.org/10.1109/LGRS.2016.2626320.

Liao, L., and R. Meneghini, 2009: Validation of TRMM Precipitation Radar through comparison of its multiyear measurements with ground-based radar. J. Appl. Meteor. Climatol., 48, 804-817, https://doi.org/10.1175/2008JAMC1974.1.
,-- , and T. Iguchi, 2001: Comparisons of rain rate and reflectivity factor derived from the TRMM Precipitation Radar and the WSR-88D over the Melbourne, Florida, site. J. Atmos. Oceanic Technol., 18, 1959-1974, https://doi.org/10.1175/15200426(2001)018<1959:CORRAR > 2.0.CO;2.

Louf, V., A. Protat, R. A. Warren, S. M. Collis, D. B. Wolff, S. Raunyiar, C. Jakob, and W. A. Petersen, 2018: An integrated approach to weather radar calibration and monitoring using ground clutter and satellite comparisons. J. Atmos. Oceanic Technol., https://doi.org/10.1175/JTECHD-18-0007.1, in press.

Meneghini, R., T. Iguchi, T. Kozu, L. Liao, K. Okamoto, J. A. Jones, and J. Kwiatkowski, 2000: Use of the surface reference technique for path attenuation estimates from the TRMM Precipitation Radar. J. Appl. Meteor., 39, 2053-2070, https:// doi.org/10.1175/1520-0450(2001)040<2053:UOTSRT>2.0.CO;2.

_ J. A. Jones, T. Iguchi, K. Okamoto, and J. Kwiatkowski, 2004: A hybrid surface reference technique and its application to the TRMM Precipitation Radar. J. Atmos. Oceanic Technol., 21, 1645-1658, https://doi.org/10.1175/JTECH1664.1.

Munchak, S. J., and C. D. Kummerow, 2011: A modular optimal estimation method for combined radar-radiometer precipitation profiling. J. Appl. Meteor. Climatol., 50, 433-448, https:// doi.org/10.1175/2010JAMC2535.1.

- - _ , and G. Elsaesser, 2012: Relationships between the raindrop size distribution and properties of the environment and clouds inferred from TRMM. J. Climate, 25, 2963-2978, https://doi.org/10.1175/JCLI-D-11-00274.1.

Park, S., S.-H. Jung, and G. Lee, 2015: Cross validation of TRMM PR reflectivity profiles using 3D reflectivity composite from the ground-based radar network over the Korean Peninsula. J. Hydrometeor., 16, 668-687, https://doi.org/10.1175/JHM-D14-0092.1.

Radhakrishna, B., and T. N. Rao, 2010: Differences in cyclonic raindrop size distribution from southwest to northeast monsoon season and from that of noncyclonic rain. J. Geophys. Res., 115, D16205, https://doi.org/10.1029/2009JD013355.

Rodgers, C. D., 2000: Inverse Methods for Atmospheric Sounding: Theory and Practice, Series on Atmospheric, Oceanic and Planetary Physics, Vol. 2, World Scientific, 238 pp.

Schumacher, C., and R. A. Houze, 2000: Comparison of radar data from the TRMM satellite and Kwajalein Oceanic Validation site. J. Appl. Meteor., 39, 2151-2164, https://doi.org/10.1175/ 1520-0450(2001)040<2151:CORDFT $>2.0 . C O ; 2$.

Schwaller, M. R., and K. R. Morris, 2011: A ground validation network for the Global Precipitation Measurement Mission. J. Atmos. Oceanic Technol., 28, 301-319, https://doi.org/10.1175/ 2010JTECHA1403.1.

Testud, J., S. Oury, R. A. Black, P. Amayenc, and X. Dou, 2001: The concept of "normalized" distribution to describe raindrop spectra: A tool for cloud physics and cloud remote sensing. J. Appl. Meteor., 40, 1118-1140, https://doi.org/10.1175/15200450(2001) $040<1118:$ TCONDT $>2.0$. CO;2.

Thompson, E. J., S. A. Rutledge, B. Dolan, M. Thurai, and V. Chandrasekar, 2018: Dual-polarization radar rainfall estimation over tropical oceans. J. Appl. Meteor. Climatol., 57, 755-775, https://doi.org/10.1175/JAMC-D-17-0160.1.

Ulbrich, C. W., and D. Atlas, 1998: Rainfall microphysics and radar properties: Analysis methods for drop size spectra. J. Appl. Meteor., 37, 912-923, https://doi.org/10.1175/15200450(1998)037<0912:RMARPA > 2.0.CO;2.

Wang, J., and D. B. Wolff, 2009: Comparisons of reflectivities from the TRMM Precipitation Radar and ground-based radars. 
J. Atmos. Oceanic Technol., 26, 857-875, https://doi.org/10.1175/ 2008JTECHA1175.1.

Wen, Y., Y. Hong, G. Zhang, T. J. Schuur, J. J. Gourley, Z. Flamig, K. R. Morris, and Q. Cao, 2011: Cross validation of spaceborne radar and ground polarimetric radar aided by polarimetric echo classification of hydrometeor types. J. Appl. Meteor. Climatol., 50, 1389-1402, https://doi.org/ 10.1175/2011JAMC2622.1.
Wolff, D. B., and B. L. Fisher, 2008: Comparisons of instantaneous TRMM ground validation and satellite rain-rate estimates at different spatial scales. J. Appl. Meteor. Climatol., 47, 22152237, https://doi.org/10.1175/2008JAMC1875.1.

, D. A. Marks, E. Amitai, D. S. Silberstein, B. L. Fisher, A. Tokay, J. Wang, and J. L. Pippitt, 2005: Ground validation for the Tropical Rainfall Measuring Mission (TRMM). J. Atmos. Oceanic Technol., 22, 365-380, https://doi.org/10.1175/JTECH1700.1. 